\title{
Accumulation of an unprecedented 5'-deoxyadenos-4'-yl radical unmasks the kinetics of the radical-mediated C-C bond formation step in MoaA catalysis
}

Haoran Pang ${ }^{1}$, Edward A. Lilla ${ }^{1}$, Pan Zhang ${ }^{2}$, Du Zhang ${ }^{2}$, Thomas P. Shields ${ }^{3}$, Lincoln G. Scott ${ }^{3}$, Weitao Yang ${ }^{2}$ and Kenichi Yokoyama ${ }^{1,2, *}$

${ }^{1}$ Department of Biochemistry, Duke University School of Medicine, Durham, North Carolina 27710, USA.

${ }^{2}$ Department of Chemistry, Duke University, Durham, North Carolina 27710, USA.

${ }^{3}$ Cassia, LLC, 3030 Bunker Hill St., Ste. 214, San Diego, CA 92109, USA.

${ }^{*}$ Corresponding Author: ken.yoko@duke.edu 


\section{Abstract:}

Radical S-adenosyl-L-methionine (SAM) enzymes catalyze various free radical-mediated reactions. In these enzymes, the rate-determining SAM cleavage kinetically masks all the subsequent steps. Due to this kinetic masking, detailed mechanistic characterization of radical transformations catalyzed by these enzymes is very difficult. Here, we report a successful kinetic characterization of the radical C-C bond formation catalyzed by a MoaA radical SAM enzyme. MoaA catalyzes an unprecedented 3',8-cyclization of GTP into 3',8-cyclo-7,8dihydro-GTP $\left(3^{\prime}, 8-\mathrm{CH}_{2}\right.$ GTP) during the molybdenum cofactor (Moco) biosynthesis. Through a series of EPR and biochemical characterization, we found that MoaA accumulates a 5'-deoxyadenos-4'-yl radical (5'-dA-C4'•) under the turnover conditions, and forms (4'S)-5'-deoxyadenosine ((4'S)-5'-dA), which is a C-4' epimer of the naturally occurring (4'R)-5'-dA. Together with kinetic characterizations, these observations revealed the presence of a shunt pathway in which an on-pathway intermediate, GTP C-3' radical, abstracts $\mathrm{H}-4^{\prime}$ atom from 5'-dA to transiently generate $5^{\prime}-\mathrm{dA}-\mathrm{C} 4^{\prime} \cdot$ that is subsequently reduced stereospecifically to yield $\left(4^{\prime} S\right)-5^{\prime}-\mathrm{dA}$. Detailed kinetic characterization of the shunt and the main pathways provided the comprehensive view of MoaA kinetics, and determined the rate of the on-pathway 3',8-cyclization step as $2.7 \pm 0.7 \mathrm{~s}^{-1}$. Together with DFT calculations, this observation suggested that the $3^{\prime}, 8$-cyclization is accelerated by $6 \sim 9$ orders of magnitude by MoaA. Potential contributions of the active-site amino acid residues, and their potential relationships with human Moco deficiency disease are discussed. This is the first determination of the magnitude of catalytic rate acceleration by a radical SAM enzyme, and provides the foundation for understanding how radical SAM enzymes achieve highly specific radical catalysis. 


\section{Introduction:}

Radical S-adenosyl-L-methionine (SAM) enzymes ${ }^{1}$ are emerging group of enzymes catalyzing unique and chemically challenging reactions by free-radical mediated mechanisms. These enzymes carry out reductive cleavage of SAM using an oxygen-sensitive [4Fe-4S] cluster (Figure 1A), and transiently generate 5'deoxyadenosyl radical $\left(5^{\prime}-\mathrm{dA} \bullet\right)$ to initiate radical-mediated catalysis. Despite the abundance of radical SAM enzymes and the diversity of chemical reactions they catalyze $\mathrm{e}^{2-3}$, many fundamental aspects of the catalytic mechanisms of radical SAM enzymes remain ambiguous. It is largely unknown how these enzymes control the reactivities of radical intermediates to achieve the reaction specificity, and how much catalytic rate acceleration is provided by the enzyme active site environment. Therefore, contributions from the enzyme active site environment are frequently not considered. This significant knowledge gap is caused at least partly because all the radical chemistry is kinetically masked by the preceding slow SAM cleavage step, and thus not mechanistically tractable. Kinetic unmasking of the radical chemistry is the first critical step to understand the mechanism of radical catalysis by radical SAM enzymes. Here, using MoaA, an essential enzyme in Molybdenum cofactor (Moco) biosynthetic pathway, we report the first determination of the rate constant for the radicalmediated $\mathrm{C}-\mathrm{C}$ bond formation in radical SAM enzymes. This work provides, to our knowledge, the first experimental evidence that a radical SAM enzyme accelerates a radical mediated reaction.

Moco is a redox enzyme cofactor found in all domains of life ${ }^{4-8}$. Moco-dependent enzymes play key steps in many biological pathways critical for life including purine and sulfur catabolism, anaerobic respiration, and nitrate assimilation ${ }^{5}$. While a salvage pathway was recently suggested in nematodes ${ }^{9}$, most organisms are thought to be incapable of taking up Moco as a nutrient due to the cofactor's chemical instability, making the de novo Moco biosynthesis an essential process. In humans, Moco biosynthesis is essential for healthy development of brains. Inability to biosynthesize Moco causes fatal metabolic disorder, Moco deficiency $(\mathrm{MoCD})^{10}$. In bacteria, some of the Moco-dependent enzymes are involved in the virulence of several clinically important pathogens, such as Mycobacterium tuberculosis ${ }^{11}$ and Pseudomonas aeruginosa ${ }^{12}$. In all organisms, the characteristic pterin backbone structure of Moco is biosynthesized by a set of conserved enzymes through the transformation of GTP into cyclic pyranopterin monophosphate (cPMP) (Figure 1B) ${ }^{6,13}$. In bacteria, this transformation is catalyzed by two enzymes, MoaA and MoaC. MoaA catalyzes the transformation of GTP into an oxygen sensitive intermediate, 3',8-cyclo-7,8-dihydro-GTP $\left(3^{\prime}, 8-\mathrm{cH}_{2} \mathrm{GTP}\right)^{14}$, which is then transformed into cPMP by a complex rearrangement catalyzed by MoaC (Figure 1B) $)^{15}$.

The MoaA catalysis has been proposed to proceed through a hydrogen atom abstraction from the 3'position of GTP by $5^{\prime}-\mathrm{dA} \cdot(\text { Figure } 1 \mathrm{C})^{14}$. The resulting GTP C-3' radical (GTP-C3'•) attacks C-8 of guanine to generate a 3',8-cyclo-GTP aminyl radical, which is converted to 3',8- $\mathrm{CH}_{2} \mathrm{GTP}$ by transfers of an electron and a proton. Among the later steps after SAM cleavage, the addition of GTP-C3'• to C-8 is likely the most chemically challenging step. Nucleotide C-3' radicals have been reported as intermediates of several biochemical reactions, including the reactions catalyzed by ribonucleotide reductase (RNR), and an oxidative damage of DNA. In RNR, C-3' radical facilitates dissociation of $2^{\prime}-\mathrm{OH}$ during the formation of deoxynucleotides ${ }^{16-18}$. Perturbations in the active site that prevents the completion of RNR catalysis most frequently result in base dissociation ${ }^{19-21}$. C-3' radical-mediated base dissociation was also reported for oxidative damage of DNA ${ }^{22}$. Thus, the addition of GTP- 
C3'• to C-8 is an unprecedented reactivity of C3' radical in either biological or synthetic reactions. The mechanism by which MoaA catalyzes this unprecedented C3'-C8 cyclization is unknown.

In this work, we initially aimed to kinetically and spectroscopically characterize the MoaA catalysis, which resulted in an observation of an organic radical species. Characterization of this radical by EPR using a series of site-specifically ${ }^{2} \mathrm{H}$ or ${ }^{13} \mathrm{C}$-labeled SAM isotopologues revealed the observed radical as 5'-deoxyadenos-4'-yl radical $\left(5^{\prime}-\mathrm{dA}-\mathrm{C} 4^{\prime} \bullet\right)$. When the reaction was performed with $\left[3^{\prime}-{ }^{2} \mathrm{H}\right] \mathrm{GTP}, 5^{\prime}-\mathrm{dA}-\mathrm{C} 4^{\prime} \cdot$ with a deuterium at the $5^{\prime}$ position was observed, suggesting that 5'-dA-C4'• was formed after the transfer of hydrogen from 3'-position of GTP to 5'-dA. Upon revisiting the MoaA reaction products, we observed formation of (4'S)-5'-dA, a 4'-epimer of $\left(4^{\prime} R\right)-5^{\prime}-\mathrm{dA}$ produced by the reductive cleavage of SAM. Kinetic characterization of formations of all the products and 5'-dA-C4'• and their global analysis allowed us to propose a refined model for MoaA catalysis. In this model, after abstraction of $\mathrm{H}-3^{\prime}$ atom from GTP by $5^{\prime}-\mathrm{dA} \cdot$, the reaction diverges to two pathways; the normal pathway that yields 3',8-cH ${ }_{2}$ GTP and (4'R)-5'-dA and a shunt pathway that yields (4'S)-5'-dA via 5'-dA-C4'•. This analysis also determined the rate constant for the on-pathway $3^{\prime}, 8$-cyclization step to be $2.7 \pm 0.7 \mathrm{~s}^{-1}$. Since DFT calculation suggested that the $3^{\prime}, 8$-cyclization of GTP in solution without catalysis would proceed at a rate of $10^{-}$ ${ }^{6} \sim 10^{-9} \mathrm{~s}^{-1}$, the observed kinetics suggested that MoaA accelerates the 3',8-cyclization by $6 \sim 9$ orders of magnitude. To our knowledge, this is the first kinetic characterization of the post-SAM cleavage reactions and the first estimation for the magnitude of rate acceleration for a radical reaction catalyzed by a radical SAM enzyme. These observations provide the foundation to understand the mechanism by which MoaA catalyzes the chemically challenging 3',8-cyclization, and contribute to our understanding of the mechanism by which radical SAM enzymes catalyze highly specific radical reactions. 


\section{Results:}

\section{Observation of an organic radical species in MoaA reaction}

To better elucidate the mechanism of MoaA catalysis, we initially characterized wt-MoaA using X-band EPR spectroscopy. The anaerobically purified and reconstituted MoaA carried $5.8 \pm 0.6$ Fe per monomer, corresponding to $1.45 \pm 0.15$ eq. of $4 \mathrm{Fe}-4 \mathrm{~S}$ cluster per monomer. In the absence of substrates, the EPR spectrum of MoaA at $15 \mathrm{~K}$ showed features that can be simulated as a sum of two axial signals (Figure $2 \mathrm{~A}$ ). The narrower signal was designated as species 1 , and the wider signal as species 2 . The $g$ values and the ratio of the two signals are listed in Table 1. The ratio of the two axial signals and the total spin concentration were not affected by the presence of SAM, but the presence of GTP slightly increased the amount of reduced clusters (from 0.94 \pm 0.09 eq. to $1.11 \pm 0.06$ eq. per monomer) and significantly increased the population of the species 2 (Figure 2B and 2C, Table 1). The two signals were not affected by the nature of the buffer systems (Tris, HEPES, or triethanolamine; Figure S1), and thus suggest the presence of two [4Fe-4S] ${ }^{+}$cluster species whose ratio shifts in a GTP-dependent manner. The nature of the two species is currently unknown.

Remarkably, in the presence of both GTP and SAM, an additional feature at $\mathrm{g}=2.0$ was observed (Figure 2D). When the EPR spectra were determined between $15 \sim 90 \mathrm{~K}$, the new feature became better resolved as the temperature increases from 15 to $45 \mathrm{~K}$ (Figure $3 \mathrm{~A}$ ). The intensity of this signal decreased at temperatures above $55 \mathrm{~K}$. The observed temperature dependent behavior of this signal suggested that it is likely an organic radical with a fast spin relaxation property.

At $45 \mathrm{~K}$, the spectrum had approximately $\sim 100 \mathrm{G}$ width centered at $g=2.0$, consistent with an organic radical (Figure 3B, black trace). Intriguingly, we observed a distinct EPR spectrum when [3'- $\left.{ }^{2} \mathrm{H}\right] \mathrm{GTP}$ was used as substrate (Figure 3C, black trace). We hereby tentatively designate the signal observed with GTP with natural isotope abundance as $X$, and the signal with $\left[3^{\prime}-{ }^{2} \mathrm{H}\right] \mathrm{GTP}$ as $\mathrm{Y}$. Radical $X$ was simulated with hyperfine coupling to three $S=1 / 2$ nuclei, suggesting the presence of three protons adjacent to the radical (Figure 3B, red trace, Table 2). Radical $Y$ spectrum was simulated by parameters identical to $X$, but with one of the three $S=1 / 2$ nuclei replaced with a $S=1$ nucleus (Figure 3C, red trace, Table 2). These observations suggested that $X$ and $Y$ represent the same radical species with different hyperfine splitting patterns due to the replacement of one of the three ${ }^{1} \mathrm{H}$ with ${ }^{2} \mathrm{H}$.

\section{The observed organic radical exhibits a unique relaxation property}

In general, organic radicals are best characterized at $\sim 77 \mathrm{~K}$. However, the radicals $\mathrm{X}$ and $\mathrm{Y}$ were broadened and less intense at $77 \mathrm{~K}$ than at $45 \mathrm{~K}$, indicating its fast relaxation property. Thus, radical $X$ was investigated by microwave power saturation experiments. When the radical signal intensities were quantified and plotted against the root square of microwave power, no apparent signal saturation was observed up to 16 $\mathrm{mW}$ and only a partial saturation was observed even at the highest possible microwave power, $200 \mathrm{~mW}$. The resulting data were analyzed by a non-linear curve fit to the following equation ${ }^{23}$ (Figure 4):

$$
\text { signal intensity }=\frac{K \times \sqrt{P}}{\left[1+\left(P / P_{1 / 2}\right)\right]^{0.5 b}}
$$


$K$ is a scaling factor, $P$ represents microwave power in milliwatts and $P_{1 / 2}$ is the microwave power at half saturation, and $b$ is the inhomogeneity parameter ${ }^{24}$. The analysis revealed $P_{1 / 2}=34.5 \pm 10.8 \mathrm{~mW}$ with $b=0.68$ \pm 0.08 . The observed $P_{1 / 2}$ was significantly larger than those reported for organic radical without any other paramagnetic centers. In the radical SAM enzyme PolH, the substrate radical trapped in a C209A mutant enzyme active site exhibited $P_{1 / 2}=23.3 \pm 17.7 \mu \mathrm{W}$ at $77 \mathrm{~K}(\text { Figure } \mathrm{S} 1)^{25}$. Similarly, characterization of a substrate radical observed in Cfr requires a low microwave power $(20 \mu \mathrm{W})$ to avoid saturation ${ }^{26}$. In BtrN, another member belongs to SPASM/Twitch family, a substrate radical was characterized with a microwave power of $400 \mu \mathrm{W}^{27}$ and both [4Fe-4S] clusters in the active site were proposed to be $2+$ state when the radical was formed ${ }^{28}$. On the other hand, in lysine 2,3-aminomutase (LAM), one of the substrate radicals observed was reported to have an onset of saturation at $>5 \mathrm{~mW}$ at $77 \mathrm{~K}^{29}$. The fast relaxation feature of radicals in LAM was attributed to the presence of another paramagnetic center although its identity is not yet known ${ }^{30}$. Based on all these reported observations, the relaxation property of the radical observed in MoaA was faster than any other radicals observed in other radical SAM enzymes, and suggests the presence of another paramagnetic center in the active site, most likely the reduced auxiliary [4Fe-4S] cluster.

\section{Characterization of the radical using isotopically labeled SAM}

The hyperfine splitting pattern of signal $X$ suggested the presence of three protons adjacent to the radical, which eliminates the possibility of GTP C-3' or N-7 radical. Thus, we investigated the possibility of a radical on 5'-dA using isotopically labeled SAM. SAM isotopologues were synthesized enzymatically from L-methionine and site-specifically isotope labeled ATP using recombinant SAM synthetase. The isotope labeled ATP was prepared from either glucose or ribose with corresponding isotope labeling using de novo purine biosynthetic enzymes ${ }^{31-}$ ${ }^{32}$. To investigate if the radical is indeed on $5^{\prime}-\mathrm{dA}$, we first characterized radical $X$ using $\left[\right.$ ribose $-{ }^{13} \mathrm{C}_{5}$ ]SAM. The resulting EPR spectrum showed significantly broader features with $\sim 200 \mathrm{G}$ width (Figure $5 \mathrm{~A}$, trace 2 ) with a large hyperfine coupling constant $(\sim 200 \mathrm{MHz}$, Table 2$)$ consistent with a hyperfine coupling with ${ }^{13} \mathrm{C}$. These results suggest that radical $X$ is on ribose carbon(s) of $5^{\prime}-\mathrm{dA}$.

To determine the exact location of radical $\mathrm{X}$, we prepared SAM isotopologues with either ${ }^{13} \mathrm{C}$ or ${ }^{2} \mathrm{H}$ on $4^{\prime}-$ or 5 -position. When $\left[5^{\prime}-{ }^{13} \mathrm{C}\right] \mathrm{SAM}$ was used in the reaction, only a small hyperfine coupling constant $(\sim 30 \mathrm{MHz})$ derived from the $5^{\prime}-{ }^{13} \mathrm{C}$ labeling was observed (Figure $5 \mathrm{~A}$ trace 3 , Table 2), indicating that the radical was not on C-5'. When $\left[5^{\prime}-{ }^{2} \mathrm{H}_{2}\right]$ SAM was used, two of the three major hyperfine splitting features in the EPR spectrum of radical $X$ collapsed, resulting in a signal with only one apparent hyperfine splitting (Figure 5A, trace 4). The simulation revealed that the radical was hyperfine coupled to only one $S=1 / 2$ nucleus (Table 2). These observations suggest that radical $X$ is hyperfine coupled to $\mathrm{H}-5$ ' of SAM. When $\left[4^{\prime}-{ }^{13} \mathrm{C}\right] \mathrm{SAM}$ was used, the EPR spectrum of the radical exhibited a large hyperfine splitting $(\sim 200 \mathrm{MHz})$ comparable to those observed in the reaction with [ribose- ${ }^{13} \mathrm{C}_{5}$ ] SAM (Figure $5 \mathrm{~A}$ trace 5 , Table 2 ). These observations are most consistent with radical $X$ being a 5'-deoxyadenos-4'-yl radical (5'-dA-C4'•).

The radical $Y$ was also characterized using the isotopically labeled SAM, which paralleled the observations with $X$ (Figure 5B, Table 2). While [ribose $-{ }^{13} \mathrm{C}_{5}$ ]SAM caused a large hyperfine splitting $(\sim 200 \mathrm{MHz})$, $\left[5^{\prime}-{ }^{13} \mathrm{C}\right]$ SAM resulted in a small hyperfine coupling splitting $(\sim 30 \mathrm{MHz})$, indicating that radical $\mathrm{Y}$ is not on $\mathrm{C}-5$ '. 
When $\left[5^{\prime}-{ }^{2} \mathrm{H}_{2}\right]$ SAM was used, the original two major hyperfine splitting features both collapsed, resulting in a singlet signal without any defined hyperfine splitting. When $\left[4{ }^{\prime}-{ }^{13} \mathrm{C}\right] \mathrm{SAM}$ was used, a large hyperfine splitting ( $200 \mathrm{MHz}$ ) comparable to that with [ribose $-{ }^{13} \mathrm{C}_{5}$ ]SAM was observed. All these observations suggest that radical $\mathrm{Y}$ is also on $\mathrm{C}-4^{\prime}$. The difference in the splitting patterns of radicals $X$ and $Y$ likely derives from the isotope at the 3'-position of GTP. Since the ${ }^{1} \mathrm{H}$ or ${ }^{2} \mathrm{H}$-atom at the $3^{\prime}$-position of GTP is transferred to the $5^{\prime}$-position of $5^{\prime}$-dA during the catalysis, the presence of hyperfine splitting with only two protons in radical $Y$ can be explained by the presence of one ${ }^{2} \mathrm{H}$ at the $5^{\prime}$-position of $5^{\prime}-\mathrm{dA}$. On the basis of these considerations, we propose radical $\mathrm{Y}$ as $\left[5^{\prime}-{ }^{2} \mathrm{H}\right] 5^{\prime}-\mathrm{dA}-\mathrm{C} 4^{\prime} \cdot$.

\section{Detection of (4'S)-5'-deoxyadenosine ((4'S)-5'-dA) formation}

Based on the observation of 5'-dA-C4'•, we sought for shunt products that may be derived from 5'-dAC4'•. When MoaA reaction was quenched by acid and analyzed by HPLC, we observed a small peak with retention time $\sim 2$ min earlier than $5^{\prime}$-dA formed from SAM cleavage (Figure 6A). The UV absorption spectrum of this peak was consistent with an adenine-containing molecule. The amount of this species increased with longer reaction time. The same product was observed in both MoaA reaction or MoaA/MoaC coupled reaction (Figure 6A). To determine its identity, the minor species and 5'-dA were purified by HPLC, and individually analyzed by LCMS. The two products were eluted with different retention time on LCMS, but showed an identical molecular weight (Figure 6B). Based on these observations and in light of the existence of $5^{\prime}-\mathrm{dA}-\mathrm{C} 4^{\prime} \cdot$, the minor species was assigned as (4'S)-5'-dA, a 4'-epimer of naturally occurring (4'R)-5'-dA. MoaA reactions with [3'-D]GTP also produced both (4'R)-5'-dA and (4'S)-5'-dA with +1 Da higher molecular weight (Figure S2A), demonstrating the (4'S)-5'-dA was formed after H-3' atom abstraction from GTP by 5'-dA - These observations suggest that (4'S)$5^{\prime}-\mathrm{dA}$ was formed by a reductive quenching of 5'-dA-C4'• by abstracting a nearby hydrogen atom or by transfers of a solvent exchangeable proton and an electron. When the MoaA reaction was conducted in $\mathrm{D}_{2} \mathrm{O}$, the molecular weights of $\left(4^{\prime} R\right)-5^{\prime}-\mathrm{dA}$ and $\left(4^{\prime} S\right)-5^{\prime}-\mathrm{dA}$ were identical to those in $\mathrm{H}_{2} \mathrm{O}$ (Figure S2B), suggesting (4'S)-5'-dA is formed by $5^{\prime}-\mathrm{dA}-\mathrm{C} 4^{\prime} \cdot$ abstracting a solvent non-exchangeable $\mathrm{H}$-atom. These results indicate that $5^{\prime}-\mathrm{dA}-\mathrm{C} 4^{\prime} \cdot$ is $^{\prime}$ likely a radical intermediate on a shunt pathway that is subsequently quenched to yield (4'S)-5'-dA.

\section{Kinetic characterization of MoaA catalysis}

To establish a kinetic model for MoaA catalysis, the kinetics of formations of $5^{\prime}-\mathrm{dA}-\mathrm{C}^{\prime} \cdot{ }^{\prime}, 3^{\prime}, 8-\mathrm{CH}_{2} \mathrm{GTP}$, $\left(4^{\prime} R\right)-5^{\prime}-\mathrm{dA}$ and (4'S)-5'-dA at pre-steady state were investigated. In these analyses, MoaA assays were performed with $300 \mu \mathrm{M}$ MoaA, $1 \mathrm{mM}$ SDT, $1 \mathrm{mM}$ GTP and $1 \mathrm{mM}$ SAM for $15 \sim 300 \mathrm{~s}$. To quantify 5'-dA-C4'•, the reactions manually freeze-quenched by isopentane slush bath, characterized by EPR, and quantified based on flavodoxin semiquinone standard ${ }^{33-34}$ (Figure S3). The time course of 5'-dA-C4'• formation (Figure 7A,B) revealed that $5^{\prime}-\mathrm{dA}-\mathrm{C} 4$ ' was formed in the first 2 min with the maximum amount of $1.6 \pm 0.3 \%$ of MoaA $(4.7 \pm 1.0 \mu \mathrm{M}$ with $300 \mu \mathrm{M}$ MoaA). To quantify 3',8-cH $\mathrm{CHTP}_{2},\left(4^{\prime} R\right)-5^{\prime}-\mathrm{dA}$ and (4'S)-5'-dA, the reactions were quenched by acid and analyzed by HPLC. For accurate quantitation of chemically unstable 3',8- $\mathrm{CH}_{2} \mathrm{GTP}$, MoaC was included in the assay to convert $3^{\prime}, 8-\mathrm{CH}_{2} \mathrm{GTP}$ to $\mathrm{cPMP}$, which is subsequently converted to a fluorescent derivative, compound $\mathrm{Z}(\mathrm{CmdZ})^{14,35}$. The presence of MoaC did not affect $5^{\prime}-\mathrm{dA}-\mathrm{C} 4^{\prime} \cdot$ formation (Figure S4). The lag phase caused by 
the coupled assay was estimated to be $<0.02 \mathrm{~s}$ based on Storer and Cornish-Bowden's method ${ }^{36-37}$. A residual amount of $3^{\prime}, 8-\mathrm{CH}_{2} \mathrm{GTP}$, likely due to its binding to MoaA, was quantified by derivatization to dimethylpterin $(\text { DMPT })^{14,38}$. Thus, the amount of $3^{\prime}, 8-\mathrm{cH}_{2}$ GTP was a sum of $\mathrm{CmdZ}$ and DMPT (Figure 7A,B). (4'R)-5'-dA and (4'S)-5'-dA were quantified by HPLC with authentic (4'R)-5'-dA as a standard (Figure 7A and B). As shown in Fig. 7A, there was a small but statistically significant delay in the formation of $3^{\prime}, 8-\mathrm{CH}_{2} \mathrm{GTP}$ relative to that of $\left(4^{\prime} R\right)-5^{\prime}-\mathrm{dA}$ in the first $\sim 2 \mathrm{~min}$. The formation of (4'S)-5'-dA was significantly slower than that of $5^{\prime}-\mathrm{dA}-\mathrm{C} 4^{\prime} \cdot$ with the lag phase in the first $~ 90 \mathrm{sec}$, but progressed over time and the amount of (4'S)-5'-dA exceeded that of 5'dA-C4'• after 3 min (Figure 7B).

The kinetic data of all four species were globally fit to kinetic models, among which the shunt pathway model (Figure 7C) gave the best fit. In this model, the MoaA catalysis is consisted of two paths. The main path produces 3',8-cH ${ }_{2}$ GTP and (4'R)-5'-dA via GTP-C3' radical, and represented by $\mathbf{S} \rightarrow \mathbf{I} \rightarrow \mathbf{P}$, where $\mathbf{S}$ represents MoaA in complex with GTP and SAM (Michaelis complex), I represents GTP-C3'•, and P represents 3',8-CH ${ }_{2} \mathrm{GTP}^{\prime}$ The shunt pathway that yields (4'S)-5'-dA via 5'-dA-C4'• is represented by I $\rightarrow \mathbf{I}^{\prime} \rightarrow \mathbf{P}^{\prime}$, where $\mathbf{I}^{\prime}$ represents $5^{\prime}-\mathrm{dA}$ C4'•, and $\mathbf{P}^{\prime}$ represents the shunt product (4'S)-5'-dA. The concentration of the Michaelis complex (S) was set as an invariable at $300 \mu \mathrm{M}$ based on the low $K_{d}$ values $(3 \sim 5 \mu \mathrm{M})$ and excess amounts $(1 \mathrm{mM})$ of SAM and GTP used in all the assays relative to MoaA (300 $\mu \mathrm{M})$. The amount of I was set below the EPR detection limit $(0.2$ $\mu \mathrm{M})$ because no detectable amount of GTP-C3'• was observed in our EPR characterizations.

Reversibility of each step was determined by either the kinetic fitting or available biochemical evidences. The reversibility of SAM cleavage and subsequent $\mathrm{H}$-atom abstraction can be probed by the number of deuterium atoms incorporated into 5'-dA from the substrate. While multiple deuterium atoms were found in 5'-dA formed by radical SAM enzymes that catalyze reversible SAM cleavage and $\mathrm{H}$-atom abstraction ${ }^{39-41}$, MoaA produced only singly deuterated $5^{\prime}-\mathrm{dA}$ from [3'-D]GTP ${ }^{14}$. Therefore, $\mathbf{S} \rightarrow \mathbf{I}$ was set irreversible. The product formation steps (I $\rightarrow \mathbf{P}, \mathbf{I}^{\prime} \rightarrow \mathbf{P}^{\prime}$ ) were also set irreversible because it is unlikely that the radicals are reversibly generated from these products. The reversibility of $5^{\prime}-\mathrm{dA}-\mathrm{C} 4^{\prime} \cdot$ formation from GTP-C3'• is unknown and both possibilities were investigated (Figure 7C, Figure S5A). Irreversible 5'-dA-C4'• formation model (Figure S6F) resulted in poorer fit compared to the reversible model (Figure S6F, Fig. 7C; $p$ values $1.2 \times 10^{-10}$ vs 0.063 ), suggesting that the data is more consistent with the reversible mechanism. However, the error values for $k_{3}$ and $k_{-3}$ were large, likely due to that GTP-C3'• is unquantifiable, leaving some ambiguity about the kinetic nature of the transformation between I and I'.

The acid quenching used for 5'-dA detection should have quenched the accumulated 5'-dA-C4'• to $\left(4^{\prime} R\right)$ 5'-dA, (4'S)-5'-dA or other uncharacterized molecules. Therefore, we performed kinetic fitting for cases where the acid-quenching of 5'-dA-C4'• yielded only (4'R)-5'-dA (Figure 7), only (4'S)-5'-dA (Figure S5B), both (4'R)-5'$\mathrm{dA}$ and (4'S)-5'-dA with a 1:1 ratio (Figure S5C) or other uncharacterized molecules (Figure S5D). Among these possibilities, the model in which the acid quenching converted $5^{\prime}-\mathrm{dA}-\mathrm{C} 4$ ' $\bullet$ to $\left(4^{\prime} R\right)-5^{\prime}-\mathrm{dA}$ provided the best fit.

The amount of Michaelis complex (S) may be lower than $300 \mu \mathrm{M}$ due to incomplete loading of [4Fe-4S] clusters. An estimation of $\sim 1.5$ eq. of [4Fe-4S] clusters per monomer were reconstituted successfully based on Ferrozine assay, and $\sim 1$ eq. of [4Fe-4S] clusters per monomer were reduced by SDT based on EPR characterization. Hence $150 \mu \mathrm{M}$ (Figure S5E) or $225 \mu \mathrm{M}$ (Figure S5F) of S were also tested for global fitting. 
Kinetic fitting with different amount of $\mathbf{S}$ only significantly change $k_{1}$ which represents rate determining step of the entire reaction. While the concentration of Michaelis complex affected $k_{1}$, the $k_{2}$ and $k_{3}$ values were only minimally affected $\left(k_{2}=2.5-2.7 \mathrm{~s}^{-1}, k_{3}=1.9-2.7 \mathrm{~s}^{-1}\right.$, and $\left.k_{3}=0.050-0.084 \mathrm{~s}^{-1}\right)$.

Another potential model where reductive quenching of $5^{\prime}-\mathrm{dA}-\mathrm{C} 4^{\prime} \cdot$ in the shunt pathway yields not only (4'S)-5'-dA, but also (4'R)-5'-dA (Figure S5G) was considered. Kinetic fitting with inclusion of (4'R)-5'-dA (A) into the shunt pathway resulted in an extremely low rate constant for $\mathbf{I}^{\prime} \rightarrow \mathbf{A}$, indicating reductive quenching of $5^{\prime}$-dA$C 4^{\prime} \cdot$ to $\left(4^{\prime} R\right)-5^{\prime}-\mathrm{dA}$ is unlikely. This observation is consistent with the absence of incorporation of a deuterium to (4'S)-5'-dA from solvent (Figure S2B), which suggested a specific mechanism of 5'-dA-C4'• quenching to form $\left(4^{\prime} S\right)-5 '-d A$.

The rate constants in the best global fit are shown in Fig. 7C. Most significantly, the analysis allowed determination of the rate constant for the transformation of GTP-C3'• (I) into $3^{\prime}, 8-\mathrm{CH}_{2} \mathrm{GTP}\left(\mathbf{P}, 2.7 \pm 0.7 \mathrm{~s}^{-1}\right)$. Since the aminyl radical intermediate did not accumulate at the detectable amount, the GTP-C3'• addition to C8 is likely the rate determining step of this transformation, and thus represented by $k_{2}$. The $k_{1}$ is the rate determining step of the entire reaction and consistent with the reported $k_{\text {cat }}$ value determined under steady-state conditions. The observed $k_{2}$ is 3 orders of magnitude faster than $k_{1}$, which is consistent with GTP-C3' (I) not experimentally detectable. Therefore, the presence of the kinetically competitive shunt pathway $\left(k_{3}=1.9 \pm 1.8 \mathrm{~s}^{-1}\right)$ allowed the first experimental determination of the rate constant for the kinetically masked 3',8-cyclization step. To our knowledge, this is the first determination of the rate constant of post-H-atom abstraction steps catalyzed by radical SAM enzymes.

\section{Evaluation of the catalytic rate acceleration}

To evaluate the rate constant from kinetic fitting, we compared experimentally determined rate constants and activation energies for intramolecular radical cyclization where alkyl radicals attack $\mathrm{sp}^{2}$ or $\mathrm{sp}^{1}$ carbon centers $^{42-45}$ (Table 3). The examples include the 5',8-cyclization of 2'-deoxyadenosine, which is known as a cyclopurine lesion of DNA oxidative damage and has been well-characterized using model systems. The reported rate constant for this reaction was experimentally determined as $1.6 \times 10^{5} \mathrm{~s}^{-1} 45$. While no experimental activation energy $\left(E_{\mathrm{a}}\right)$ for this reaction has been reported, a theoretical value based on DFT calculation has been reported as $8.4 \mathrm{kcal} / \mathrm{mol}^{45}$. In these examples, the natural log of the pre-exponential factors $(A)$ of the Arrhenius equation falls in a relatively narrow range of $9.5 \sim 12.1$.

Since 3',8-cyclization does not proceed in solution without enzymatic catalysis, no experimental rate constants or $E_{\mathrm{a}}$ is available. Instead, we performed a DFT calculation of the 3',8-cyclization in solution at $298 \mathrm{~K}$. Calculation of a transformation of GTP-C3'• to 3',8-cyclo-GTP aminyl radical in solution without any catalysis revealed a theoretical $E_{\mathrm{a}}$ of $24.6 \mathrm{kcal} / \mathrm{mol}$ (Fig. 8A). Assuming that the pre-exponential factor $(A)$ of the Arrhenius equation for the $3^{\prime}, 8$-cyclization is similar to those of the related radical cyclization reactions in Table 3 , the $E_{a}$ correspond to rate constants of $1.1 \times 10^{-6} \sim 2.9 \times 10^{-9} \mathrm{~s}^{-1}$. These evaluations are consistent with the absence of reported 3',8-cyclization in non-enzymatic reactions and the chemically challenging nature of this transformation. For the MoaA-catalyzed 3',8-cyclization, based on the rate constant $k_{2}=2.7 \pm 0.7 \mathrm{~s}^{-1}$ and the A value in Table 3, 
the $E_{\mathrm{a}}$ was estimated as $12.2 \sim 16.1 \mathrm{kcal} / \mathrm{mol}$. Therefore, these analyses suggest that MoaA likely stabilizes the transition state by $8.5 \sim 12.4 \mathrm{kcal} / \mathrm{mol}$, and accelerate the reaction rate by $6 \sim 9$ orders of magnitude.

We further investigated the effect of the active site environment on the $E_{a}$ of 3 ',8-cyclization. Conformational restraints were first applied to the structure of GTP-C3'•. The triphosphate moiety and O6, N1, and N2 atoms on guanine base were fixed based on the reported X-ray crystal structure ${ }^{38}$ and ENDOR analysis ${ }^{46}$ of MoaA in complex with GTP, where extensive interactions were observed between these positions of GTP and MoaA active site amino acid residues or the auxiliary cluster. The ribose moiety was not $\mathrm{H}$-bonded to any of the amino acid residues, and thus allowed to move. When this partially fixed GTP-C3'• was used, the theoretical $E_{a}$ of 3',8-cyclization was calculated as $19.2 \mathrm{kcal} / \mathrm{mol}$ (Fig. 8A), which is $\sim 5.4 \mathrm{kcal} / \mathrm{mol}$ lower than the calculation without any conformational constrains. This lowering in $E_{\mathrm{a}}$ may be explained by the energy minimized conformation of GTP-C3'• (1C in Figure 8), in which C3' is already in an orientation favorable to attack C8 with a relatively short distance between C3' and C8 (3.19 A, Figure 8A). Longer C3'-C8 distances were found in GTPC3'• without any constraints (3.54 $\AA, 1 \mathrm{~A}$ in Figure $8 \mathrm{~A})$ or in the X-ray crystal structure of MoaA•GTP complex $(3.8 \AA$ ). These observations suggest that the MoaA active site likely pre-organizes the GTP-C3'• conformation to accelerate the 3 ',8-cyclization.

The theoretical $E_{\mathrm{a}}$ determined for the conformational constraint model, however, was still higher than the estimated $E_{\mathrm{a}}$ of $12.2 \sim 16.1 \mathrm{kcal} / \mathrm{mol}$. Therefore, we investigated the effects of the three catalytically essential Arg residues (R17, R266, R268). When these residues were included in our calculation, the $E_{\mathrm{a}}$ was even lowered to $14.2 \mathrm{kcal} / \mathrm{mol}$. The Arg residues did not significantly affect the distance between C3' and C8 (3.13 $\AA$ vs 3.19 $\AA$, Figure $8 \mathrm{~A}$ ), suggesting that the lower $E_{\mathrm{a}}$ was achieved by the positive charge or the $\mathrm{H}$-bond interactions with the Arg residues. Among the three Arg residues, R17 had the greatest effect as its removal increased the $E_{\mathrm{a}}$ by $3.5 \mathrm{kcal} / \mathrm{mol}$ (Table S1). The catalytic function of R17 was also tested by activity assays of R17A- and R17KMoaA. While R17A-MoaA was catalytically inactive, R17K-MoaA exhibited activity comparable to wt-MoaA (Figure SX), suggesting that a positive charge at this position is sufficient for the catalytic function of MoaA. While the auxiliary [4Fe-4S] cluster and the disordered C-terminal tail may also contribute to the transition state stabilization, these results suggested that the conformational constraints and the positive charge provided by the Arg residues are likely important for the catalytic rate acceleration of the 3',8-cyclization by MoaA.

In all the tested conditions, the free energies of the product were close or slightly higher than those of the reactant. Since the overall transformation of GTP into 3',8- $\mathrm{cH}_{2}$ GTP is irreversible, the observation suggests that the addition of GTP C3' to C8 should be followed by a thermodynamically favorable step. Such a thermodynamic driving force could be provided by the reductive quenching of the aminyl radical. While this step was previously proposed to be catalyzed by an electron transfer from the auxiliary $4 \mathrm{Fe}-4 \mathrm{~S}$ cluster ${ }^{14}$, no experimental evidence is currently available. The mechanism of this radical quenching step is currently investigation.

Finally, we also performed DFT calculations using the enol tautomer of GTP C3'• (Table S2). Previously, the coordination of GTP N1 to the auxiliary 4Fe-4S cluster was proposed to stabilize the enol tautomer of GTP ${ }^{46}$. However, in our calculation, in the presence of the three Arg residues, the enol tautomer of GTP C3'• is 22.2 $\mathrm{kcal} / \mathrm{mol}$ less favored than the keto tautomer (Table S3), while the difference was minimal in the absence of the Arg residues $(0.75 \mathrm{kcal} / \mathrm{mol})$. Among the three Arg residues, R266 and R268 had the most significant effects 
(19.7 kcal/mol, Table S3). Therefore, in the presence of these Arg residues, the keto tautomer is likely favored. In addition, the theoretical activation energy of the 3',8-cyclization through the enol tautomer was minimally different $(1.2 \mathrm{kcal} / \mathrm{mol}$, Table S2) from that with the keto tautomer. While more comprehensive analysis including the auxiliary cluster and the C-terminal tail is needed to identify the predominant tautomer of GTP in the MoaA active site, the above observations suggest that keto-enol tautomerization has minimal to no effects on the 3',8cyclization efficiency. 


\section{Discussion:}

This study describes the comprehensive kinetic characterization of the MoaA-catalyzed reaction. EPR characterization of MoaA reactions revealed that MoaA accumulates an organic radical under turnover conditions. This radical was characterized as $5^{\prime}-\mathrm{dA}-\mathrm{C} 4^{\prime} \cdot$ using a series of isotopically labeled SAM. Intriguingly, these studies revealed that $5^{\prime}$-dA-C4'• carries ${ }^{1} \mathrm{H}$ or ${ }^{2} \mathrm{H}$ transferred from $3^{\prime}$-position of GTP, suggesting that ${ }^{1} \mathrm{H} /{ }^{2} \mathrm{H}-3^{\prime}$ abstraction precedes the 5'-dA-C4'• formation. Subsequent search for shunt products identified the formation of (4'S)-5'-dA. Based on these observations, we proposed a presence of a shunt pathway that produces (4'S)-5'-dA via 5'-dAC4'• (Fig. 9). The shunt pathway diverges from the main pathway from GTP-C3'•. While in the main pathway, GTP-C3'• undergoes the intramolecular addition to C-8 to accomplish the 3',8-cyclization, in the shunt pathway, GTP-C3'• abstracts a $\mathrm{H}$-atom from the $4^{\prime}$-position of $5^{\prime}-\mathrm{dA}$, resulting in the formation of $5^{\prime}-\mathrm{dA}-\mathrm{C} 4^{\prime} \cdot$. The resulting $5^{\prime}-\mathrm{dA}-\mathrm{C} 4$ '• is subsequently quenched by abstracting a solvent non-exchangeable hydrogen from a currently unknown hydrogen donor to yield (4'S)-5'-dA. Comprehensive kinetic characterization of all the characterized products and 5'-dA-C4'• was also consistent with the proposed model. As described in detail below, the kinetic analysis successfully provided the kinetic constant for the radical-mediated C-C bond formation reaction as 2.7 $\pm 0.7 \mathrm{~s}^{-1}$, which was kinetically unmasked from the preceding rate-determining step (most likely to be the SAM cleavage step) and provided the first evidence that MoaA significantly accelerates this unprecedented 3',8cyclization.

Kinetically competitive shunt reactions are rare in radical SAM enzymes. Despite the highly reactive nature of radical species, radical SAM enzymes generally catalyze specific chemistry, and rarely catalyzes shunt reactions. Most of the unnatural reactions catalyzed by radical SAM enzymes are reported for reactions with mutant enzymes or unnatural substrates, such as DesIl, which is a deaminase on its native substrate TDP-4amino-4,6-dideoxy-D-glucose while it acts as a dehydrogenase on an unnatural substrate TDP-D-quinovose ${ }^{47-}$ ${ }^{48}$. For wild-type enzymes with natural substrate, the only protein that catalyzes shunt reactions, to our knowledge, is NosL, which catalyzes both the cleavage of Ca-C of L-Trp to produce 3-methyl-2-indolic acid and the cleavage of C $\alpha-C \beta$ bond of L-Trp to produce 3-methylindole ${ }^{49-53}$. In the current study, MoaA was found as another wildtype radical SAM enzyme with catalytic promiscuity on its natural substrate, where GTP-C3'• can either attack C8 of guanine to form 3',8-cyclo-GTP aminyl radical or abstracts H-4' of 5'-dA to form 5'-dA-C4'•.

$5^{\prime}-\mathrm{dA}-\mathrm{C} 4^{\prime} \cdot$ is unprecedented in radical SAM enzymes, and likely represents the orientation of 5'-dA relative to GTP-C3'• during the catalysis as well as the kinetics of subsequent 3',8-cyclization. In a model active site structure of MoaA $^{14}$ (Figure 8B), the distance between GTP C3' and SAM C4' is even shorter than the distance between GTP C3' and SAM C5' (4.6 $\AA$ vs $5.4 \AA$ ). Therefore, while this model is likely still missing a significant part of the active site ${ }^{54}$, the analysis is consistent with the abstraction of $\mathrm{H}-4^{\prime}$ of $\left(4^{\prime} R\right)-5^{\prime}-\mathrm{dA}$ by GTPC3'•. However, this spatial arrangement is not unique among radical SAM enzymes. In the reported crystal structure of $B \operatorname{tr} \mathrm{N}^{55}$, the distance between $\mathrm{C} 1$ of 2-deoxy-scyllo-inosamine (DOIA) and SAM C4' is also comparable to that with SAM C5' (3.7 A vs $3.8 \AA$ ). However, the accumulation of $5^{\prime}-\mathrm{dA}-\mathrm{C} 44^{\prime} \cdot$ radical has never been observed in other radical SAM enzymes. Thus, the presence of the $5^{\prime}-\mathrm{dA}-\mathrm{C} 4^{\prime} \cdot$ accumulation and the shunt pathway should also reflect the inherently challenging nature of subsequent 3 ',8-cyclization. Our kinetic analysis revealed the rate constant $k_{2}$ for the $3^{\prime}, 8$-cyclization as $2.7 \pm 0.7 \mathrm{~s}^{-1}$. Although this value is $\sim 2000$ times faster 
than the preceding rate-determining step $\left(k_{1}=0.0013 \pm 0.00002 \mathrm{~s}^{-1}\right)$, it is still significantly slower than other radical-mediated intramolecular $\mathrm{C}-\mathrm{C}$ bond formation reactions in solution (Table 3 ). The slow 3',8-cyclization allows GTP-C3'• to abstract H-4' of 5'-dA that is also slow but comparable to the rate of 3',8-cyclization $\left(k_{3}=1.9\right.$ $\left.\pm 1.8 \mathrm{~s}^{-1}\right)$. Therefore, the structure and the kinetics of MoaA catalysis both contributed to the presence of the shunt pathway, which is likely a compromise of evolving a catalyst for the chemically challenging 3',8-cyclization.

While the MoaA-catalyzed 3',8-cyclization is slow compared to other intramolecular radical cyclization reactions (Table 3), it is significantly faster than the theoretical rate of uncatalyzed 3',8-cyclization. Our analysis suggests that MoaA likely accelerates this reaction by $6 \sim 9$ orders of magnitude, which corresponds to the stabilization of $E_{\mathrm{a}}$ by $8.5 \sim 12.4 \mathrm{kcal} / \mathrm{mol}$. This rate acceleration is moderate as an enzyme and comparable to those reported for chorismate mutase ${ }^{56}$. In chorismate mutase, the rate acceleration was proposed to be achieved by orienting the substrate to the near-attack conformation ${ }^{57-58}$ as well as by a transition state stabilization through an electrostatic interaction with an active site Arg residue ${ }^{59}$. Analogously, MoaA may accelerate the 3',8-cyclization by orienting the GTP conformation optimal for the 3',8-cyclization. In fact, in our DFT analysis, a decrease of activation energy of $\sim 5.4 \mathrm{kcal} / \mathrm{mol}$ was achieved by fixing the structure of GTP-C3'• based on the interactions between GTP and MoaA active site in the crystal and solution structures of MoaA in complex with GTP. In addition, the DFT calculation also suggested that the three catalytically essential Arg residues could also contribute to another $\sim 5 \mathrm{kcal} / \mathrm{mol}$ decrease of activation energy through electrostatic or $\mathrm{H}$ bond interaction. Among the three Arg residues, R17 had the most significant effects. Since mutations of these residues in human MoaA homolog have been reported to cause human Moco deficiency disease, understanding of their catalytic functions will not only elucidate the mechanism of MoaA catalysis, but also could provide the foundation for future development of currently incurable human Moco deficiency disease.

Our theoretical analysis also suggested that the addition of GTP C3'• to C8 is slightly endergonic, suggesting that the subsequent aminyl radical reduction needs to be thermodynamically favorable. Although the auxiliary cluster was proposed to serve as an electron donor for this transformation, no experimental evidence is currently available. Even the redox potential or redox state of the auxiliary cluster is not known. Therefore, it is notable that the redox state of the auxiliary cluster could be deduced from the spin relaxation property of 5'dA-C4'•. Substrate radicals characterized in radical SAM enzymes usually exhibit $P_{1 / 2} \ll 1 \mathrm{~mW}$ at $77 \mathrm{~K}$, a property typical for organic radicals trapped in enzyme active-site without other paramagnetic centers. Thus, the unusually fast relaxation property of the $5^{\prime}-\mathrm{dA}-\mathrm{C} 4^{\prime} \cdot$ signal is unlikely to be caused by the $\mathrm{N}$-terminal radical SAM $[4 \mathrm{Fe}-4 \mathrm{~S}]^{2+}$ cluster. The [4Fe-4S] clusters from the second subunit of the MoaA dimer is removed by more than $31 \AA$, and therefore unlikely to cause significant effects on the relaxation properties. Although further investigation is needed, it is most reasonable to conclude that the observed effect is due to the presence of the C-terminal auxiliary cluster in the paramagnetic $[4 \mathrm{Fe}-4 \mathrm{~S}]^{1+}$ state. If this cluster is in the reduced form during the catalytic cycle, it may then be responsible for the reduction of the putative aminyl radical intermediate. The redox roles have been proposed for auxiliary clusters in the radical SAM enzymes in the SPASM/Twitch family ${ }^{27,55,60}$, and the redox potentials have been reported for enzymes under resting states ${ }^{61}$. However, no experimental demonstration has been made about their redox states during the catalytic cycle. Thus, the observations 
described here represent one of the first experimental evidence for the redox state of auxiliary cluster during the catalytic cycle of any SPASM/Twitch radical SAM enzymes.

In conclusion, we report our comprehensive characterization of MoaA catalysis using EPR and biochemical methods, which revealed a unique shunt reaction that produces (4'S)-5'-dA via 5'-dA-C4'•. Detailed kinetic characterization of the shunt and main pathways allowed the determination of the rate constant for the radical mediated $\mathrm{C}-\mathrm{C}$ bond formation, which is otherwise kinetically masked by the preceding slow SAM cleavage $^{62}$. These results revealed the ability of MoaA to facilitate the chemically challenging 3',8-cyclization, and provided an important foundation to understand the mechanism of rate acceleration. Future studies of MoaA catalytic mechanisms are important to understand how radical SAM enzymes catalyze chemically challenging radical transformations to provide mechanistic bases on the cause of human Moco deficiency disease. 


\section{Associated content:}

\section{Supporting information}

Additional experimental details, supplementary methods, and extended data. This material is available free of charge via the Internet at http://pubs.acs.org.

\section{Author information:}

\section{Corresponding Author}

*ken.yoko@duke.edu

\section{Notes}

The authors declare no competing financial interest.

\section{Acknowledgement:}

This work was supported by the Duke University Medical Center and National Institute of General Medical Sciences R01 GM112838 (to K.Y.). We thank Peter Silinski for assistance with the MS measurements. We thank Benjamin G. Bobay at the Duke NMR facility for the assistance in collecting NMR data. EPR spectrometer was supported by an Institutional Development Grant (ID 2014-IDG-1017) from the North Carolina Biotechnology Center. 


\section{Figures:}

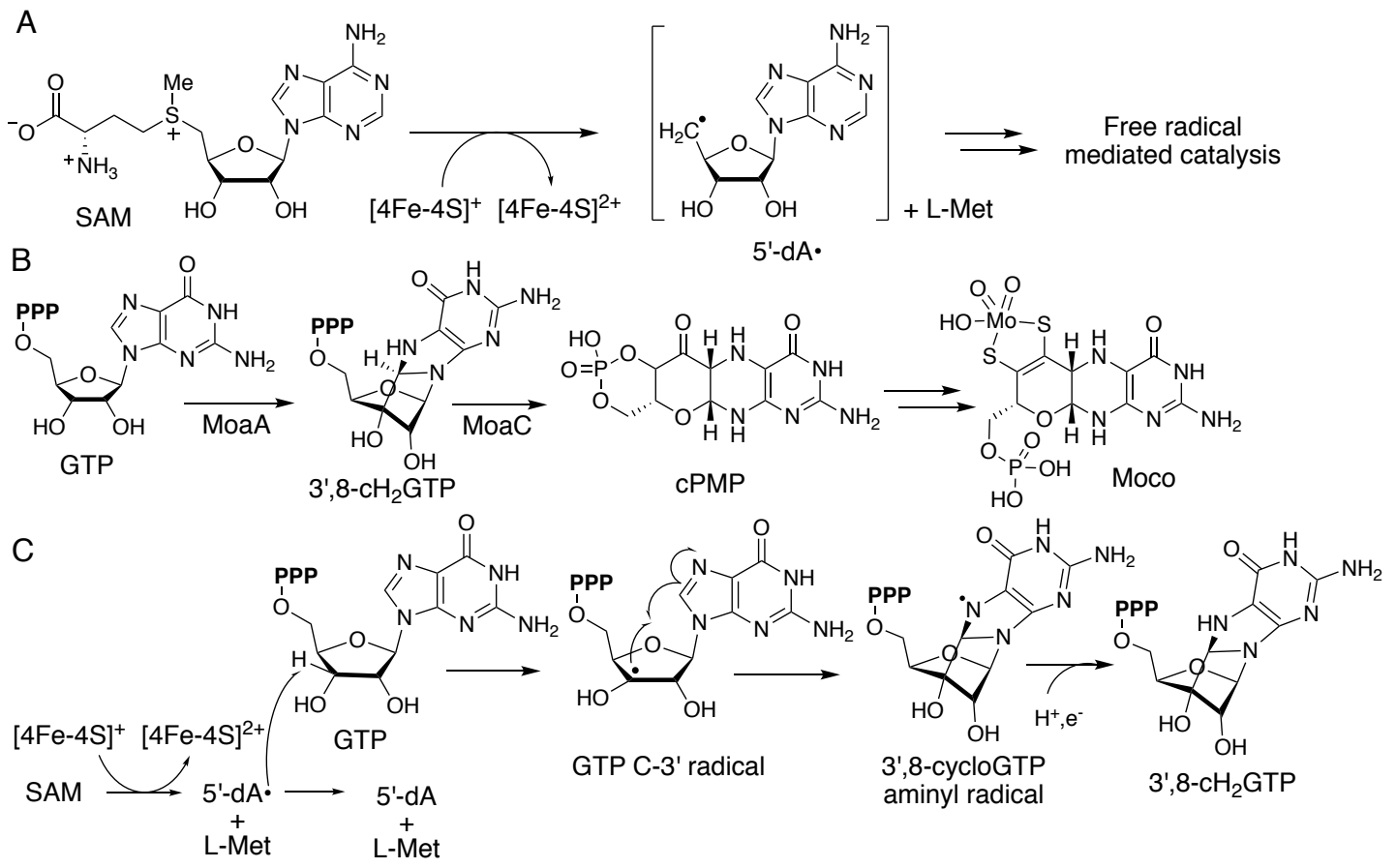

Figure 1. Moco biosynthetic pathway and proposed mechanism of MoaA. (A) SAM reductive cleavage catalyzed by radical SAM enzymes. (B) Moco biosynthetic pathway in bacteria. (C) Proposed mechanism of radicalmediated C3'-C8 bond formation by MoaA. 
bioRxiv preprint doi: https://doi.org/10.1101/2020.01.16.909697; this version posted January 17, 2020. The copyright holder for this preprint (which was not certified by peer review) is the author/funder. All rights reserved. No reuse allowed without permission.

A

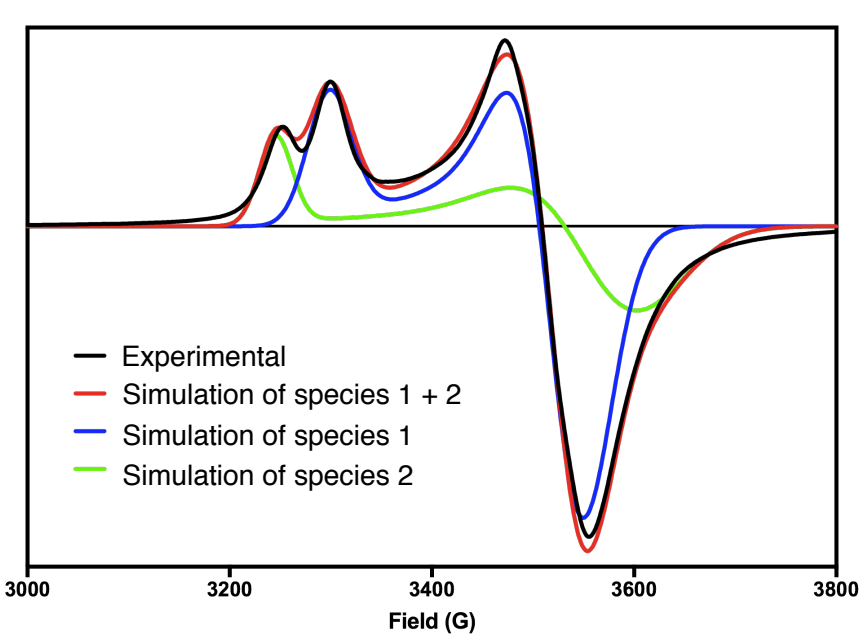

C

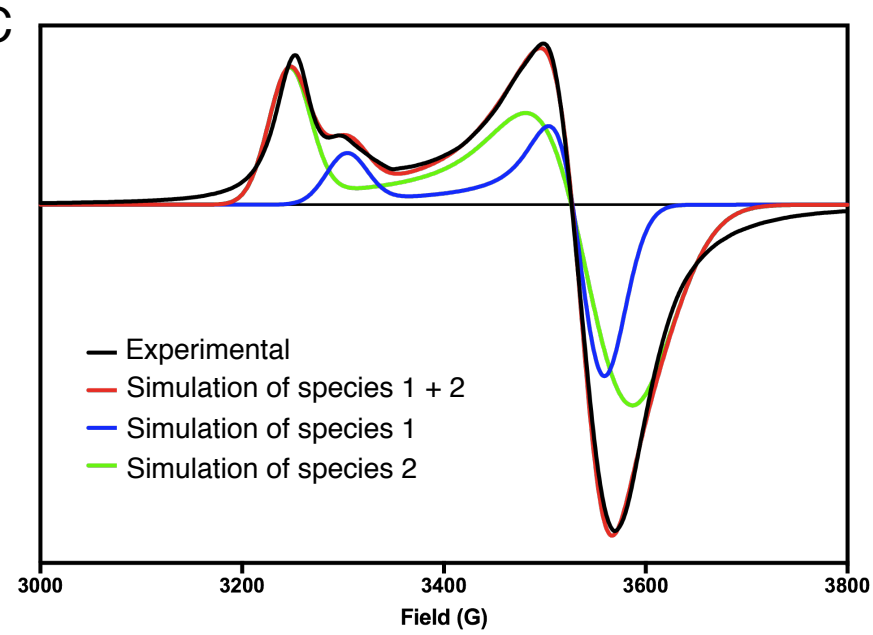

B

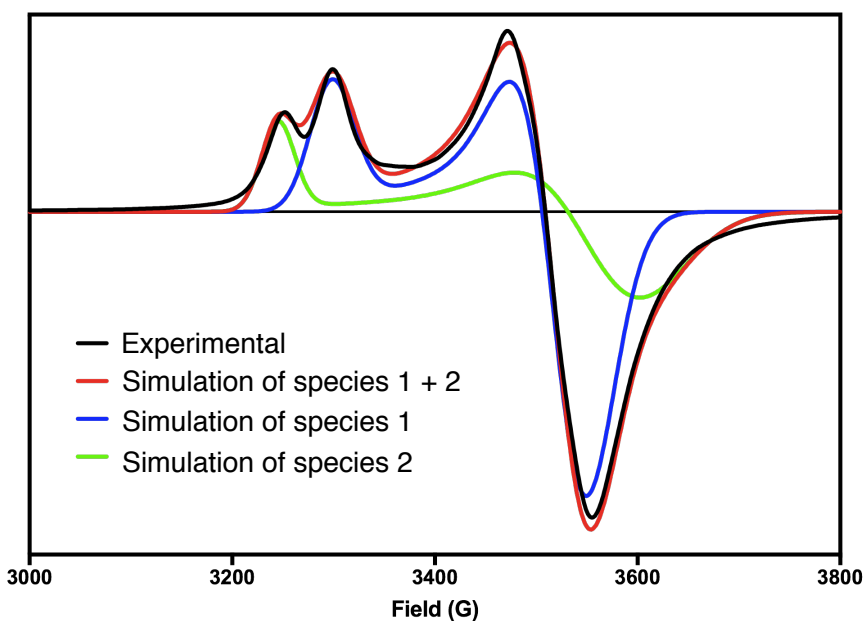

D

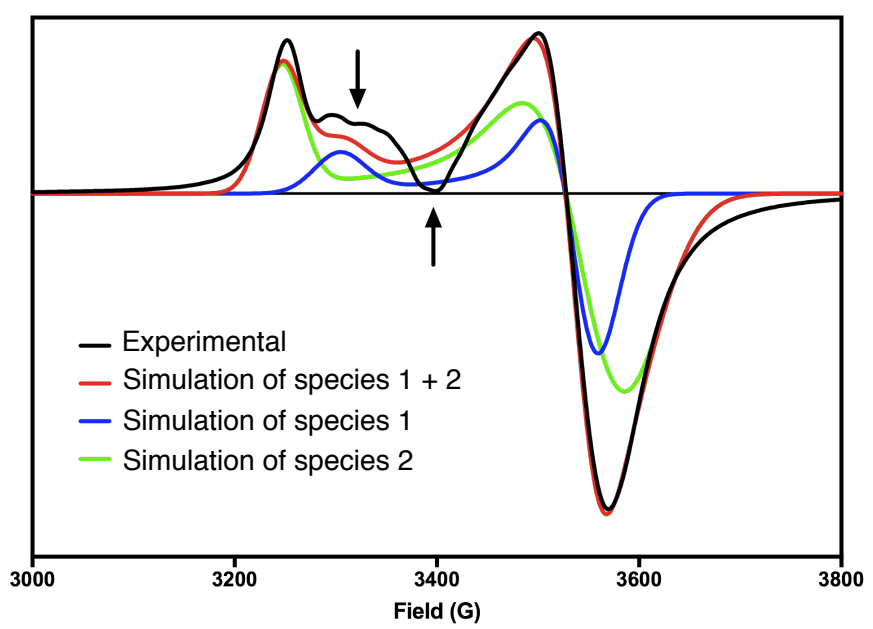

Figure 2. EPR spectra of MoaA at $15 \mathrm{~K}$. Pre-reduced MoaA was incubated with (A) buffer only, (B) SAM, (C) GTP, (D) both SAM and GTP for 2 min and manually frozen in an isopentane slush bath. 

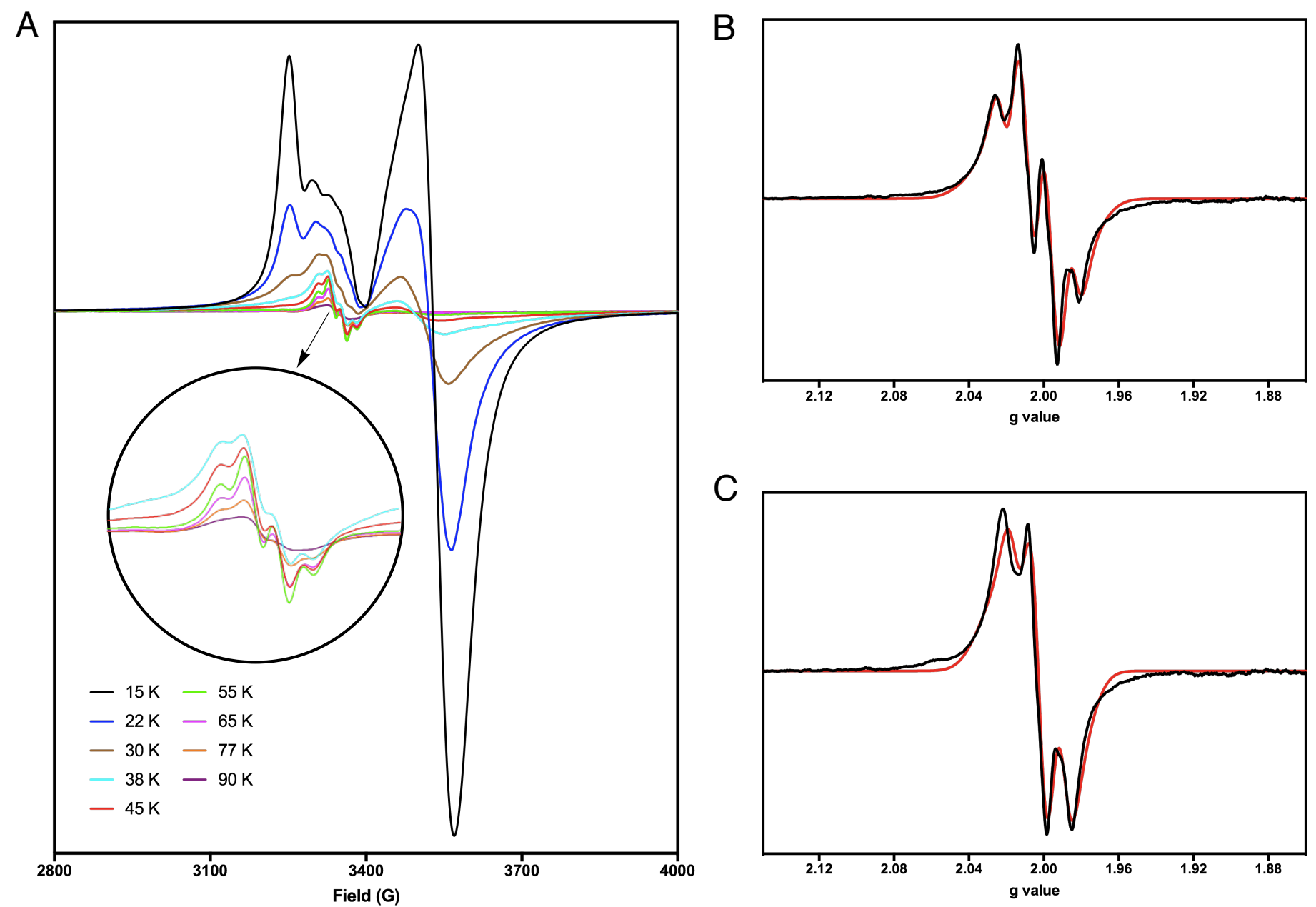

Figure 3. EPR characterization of the observed radical species. (A) Overlay of EPR spectra of MoaA under turnover conditions. The EPR spectra were determined at the temperatures shown in the figure. (B, $C)$ Experimental (black trace) and simulated EPR spectra (red trace) of radical $X(B)$ and $Y(C)$ in MoaA reaction with GTP or $\left[3^{\prime}-{ }^{2} \mathrm{H}\right] \mathrm{GTP}$ as substrate, respectively. The EPR spectra were determined at $45 \mathrm{~K}$ and the residual $[4 \mathrm{Fe}-4 \mathrm{~S}]^{+}$cluster signal was subtracted using a negative control without SAM. 


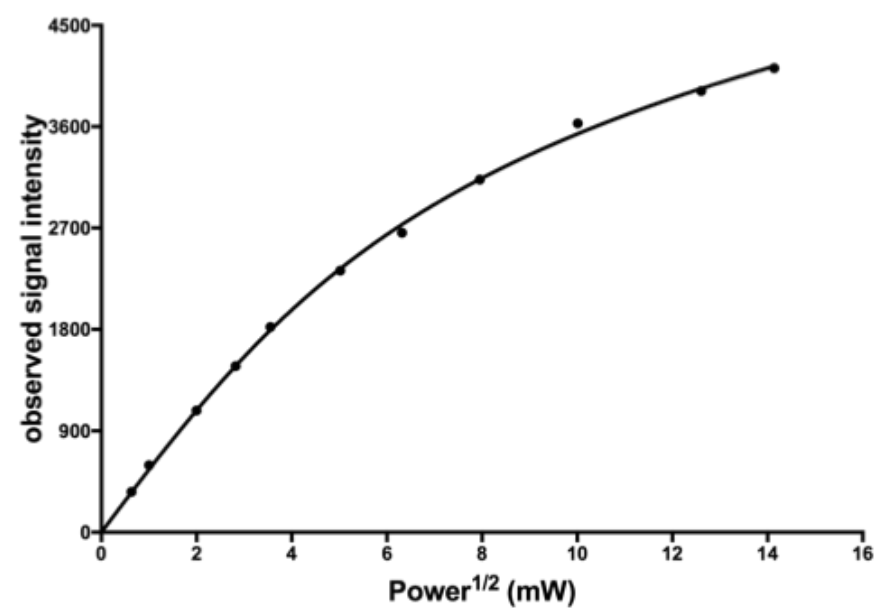

Figure 4. Relaxation property of radical $X$ measured at $45 \mathrm{~K}$. The solid line represents a non-linear curve fit to eq. 1 with $K=561.5 \pm 15.4, P_{1 / 2}=34.5 \pm 10.8 \mathrm{~mW}$, and $b=0.68 \pm 0.08$. 
bioRxiv preprint doi: https://doi.org/10.1101/2020.01.16.909697; this version posted January 17, 2020. The copyright holder for this preprint (which was not certified by peer review) is the author/funder. All rights reserved. No reuse allowed without permission.

A

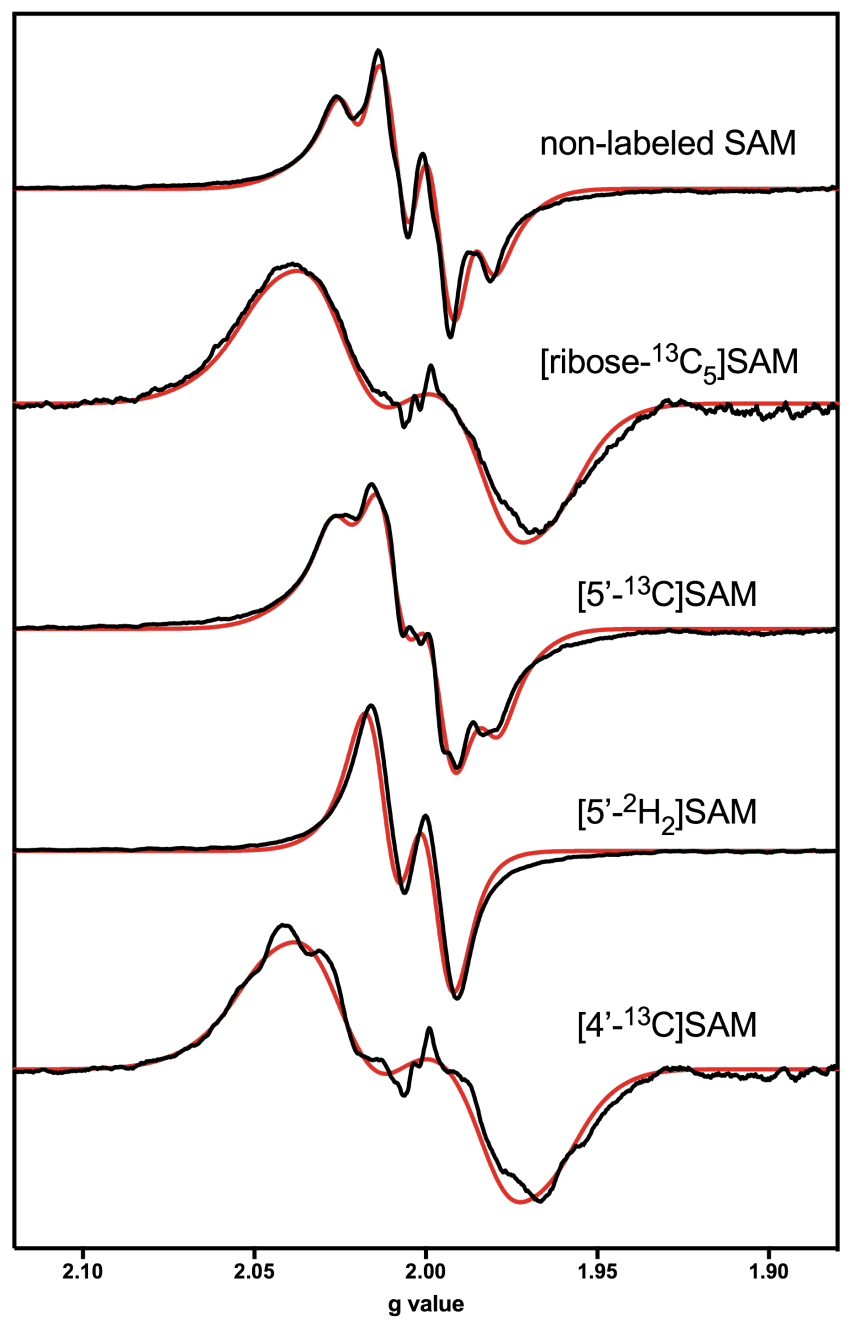

B

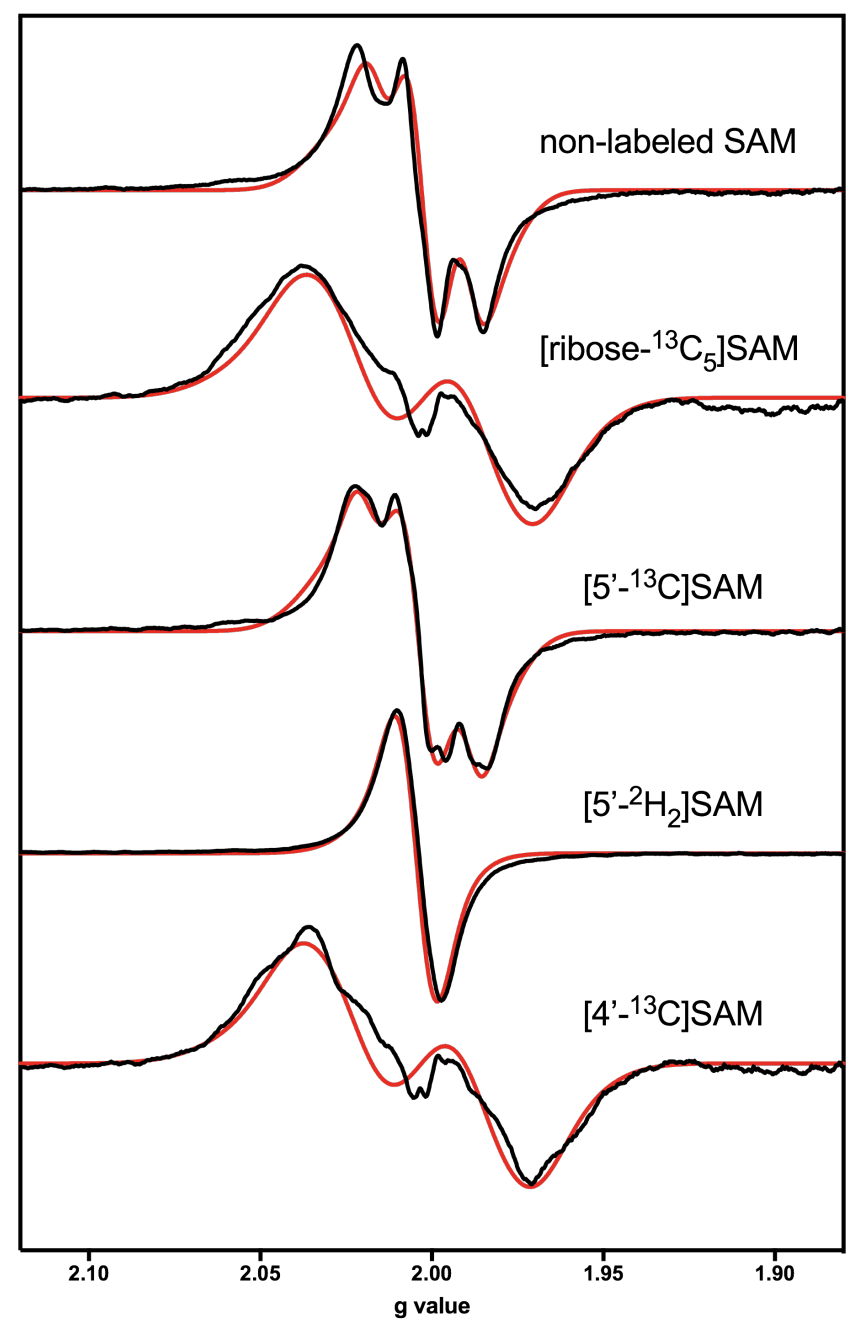

Figure 5. EPR characterization of radical $X$ and $Y$ by using isotopically labeled SAM. Shown are experimental (black traces) and simulated EPR spectra (red traces) of radicals $X(A)$ and $Y(B)$ generated in the presence of isotopically labeled SAM. 


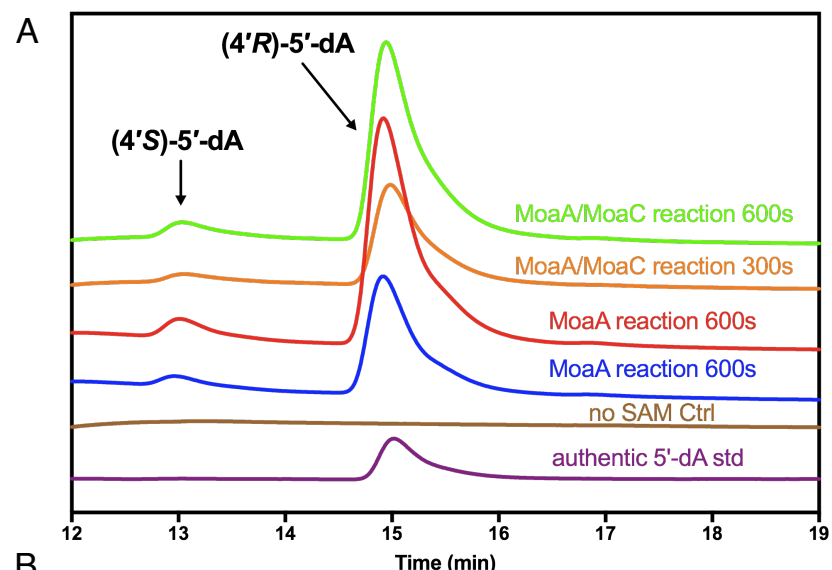

B
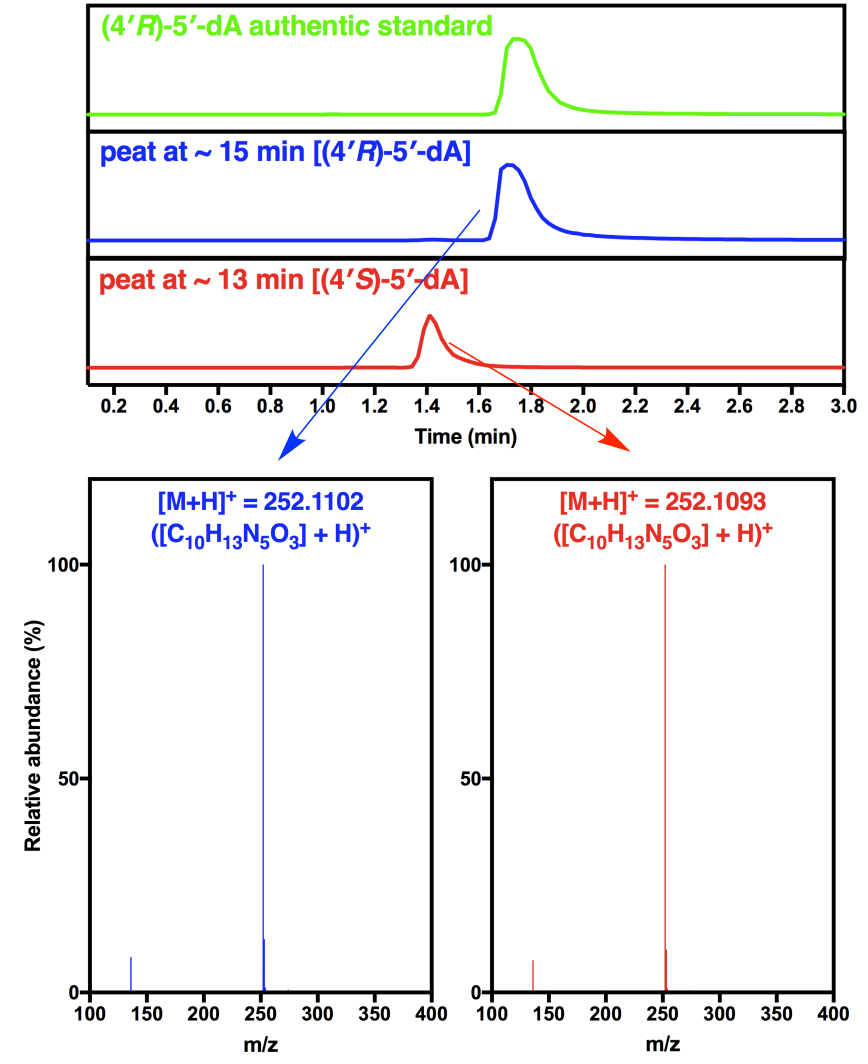

Figure 6. Formation of (4'S)-5'-dA in MoaA reaction. (A) HPLC detection of (4'S)- and (4'R)-5'-dA in MoaA assays. Shown are HPLC traces monitored at $260 \mathrm{~nm}$ for (from the bottom to the top) authentic (4'R)-5'-dA standard, a control MoaA assay without SAM, MoaA assay quenched at 300 or $600 \mathrm{~s}$, MoaA/MoaC coupled assay quenched at 300 or $600 \mathrm{~s}$. (B) LCMS characterization of (4'S)- and (4'R)-5'-dA isolated from the MoaA reaction with GTP and SAM. Shown are extracted ion chromatograms monitored at $\mathrm{m} / \mathrm{z}=252.1091$, and extracted mass spectrum at each retention time. 

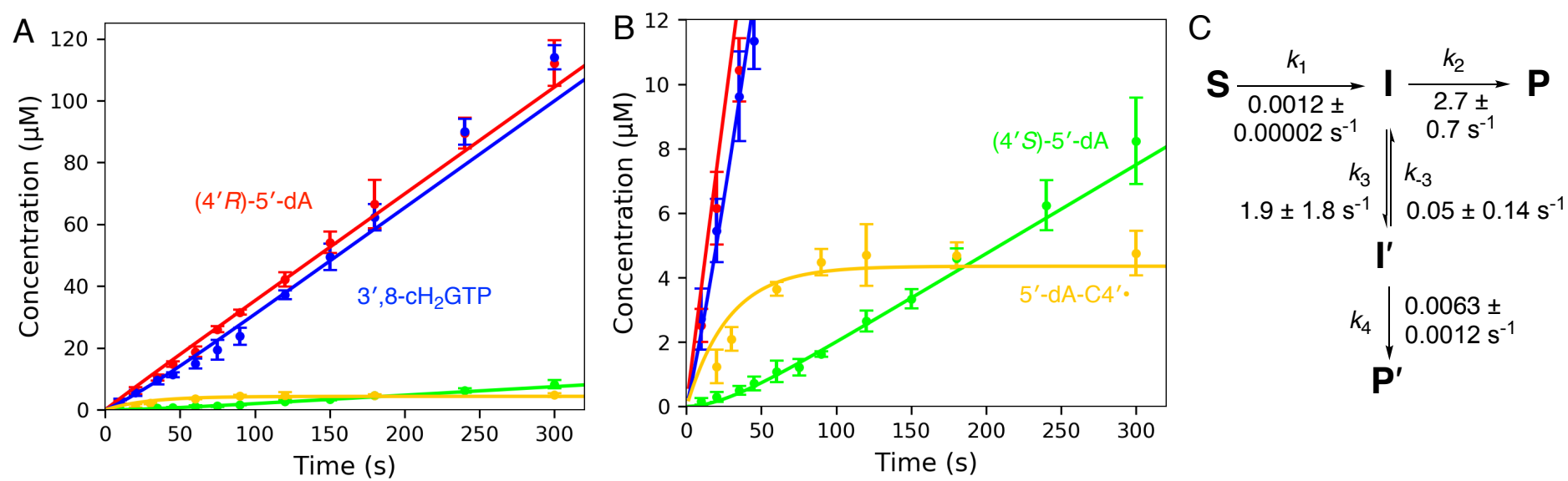

Figure 7: Kinetic model of MoaA catalysis. (A and B) Time course of formations of $5^{\prime}-\mathrm{dA}-\mathrm{C} 4^{\prime} \cdot, 3^{\prime}, 8-\mathrm{CH}_{2} \mathrm{GTP}$, $\left(4^{\prime} R\right)-5^{\prime}-\mathrm{dA}$ and $\left(4^{\prime} S\right)-5^{\prime}-\mathrm{dA}$. B is a magnified view of A focused on $5^{\prime}-\mathrm{dA}-\mathrm{C} 4^{\prime} \cdot$ and $\left(4^{\prime} S\right)-5^{\prime}-\mathrm{dA}$. The solid lines are the results of global fitting ( $p$-value of 0.063 and $x^{2} / D o F$ of 1.32) using KinTek Explorer ${ }^{63-64}$ and the parameters and the model shown in $\mathrm{C}$. (C) Kinetic model and rate constants used to analyze the time course data in $A$ and B. S, the Michaelis complex (MoaA•GTP•SAM); I, GTP-C3'•; P, 3',8-cH ${ }_{2}$ GTP and (4'R)-5'-dA; I', 5'-dA-C4'•, and $\mathbf{P}^{\prime},\left(4^{\prime} S\right)-5$ '-dA. 
A

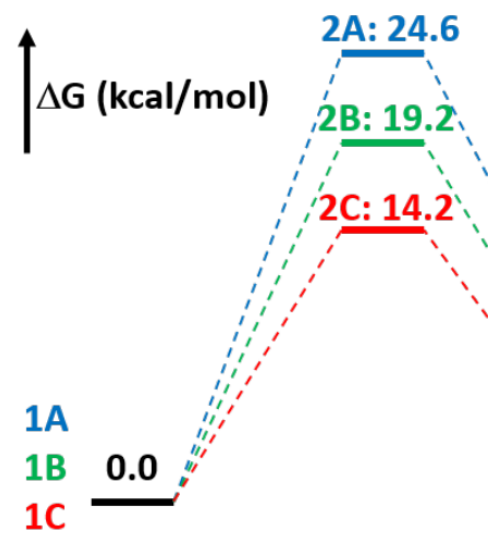

$$
\begin{aligned}
& E_{A}(A)=24.6 \mathrm{kcal} / \mathrm{mol} \\
& E_{A}(B)=19.2 \mathrm{kcal} / \mathrm{mol} \\
& E_{A}(C)=14.2 \mathrm{kcal} / \mathrm{mol}
\end{aligned}
$$

A: GTP (no restraints)

1: Reactant

B: GTP (with restraints)

2: Transition state

C: GTP+Arg (with restraints)

\section{3: Product}
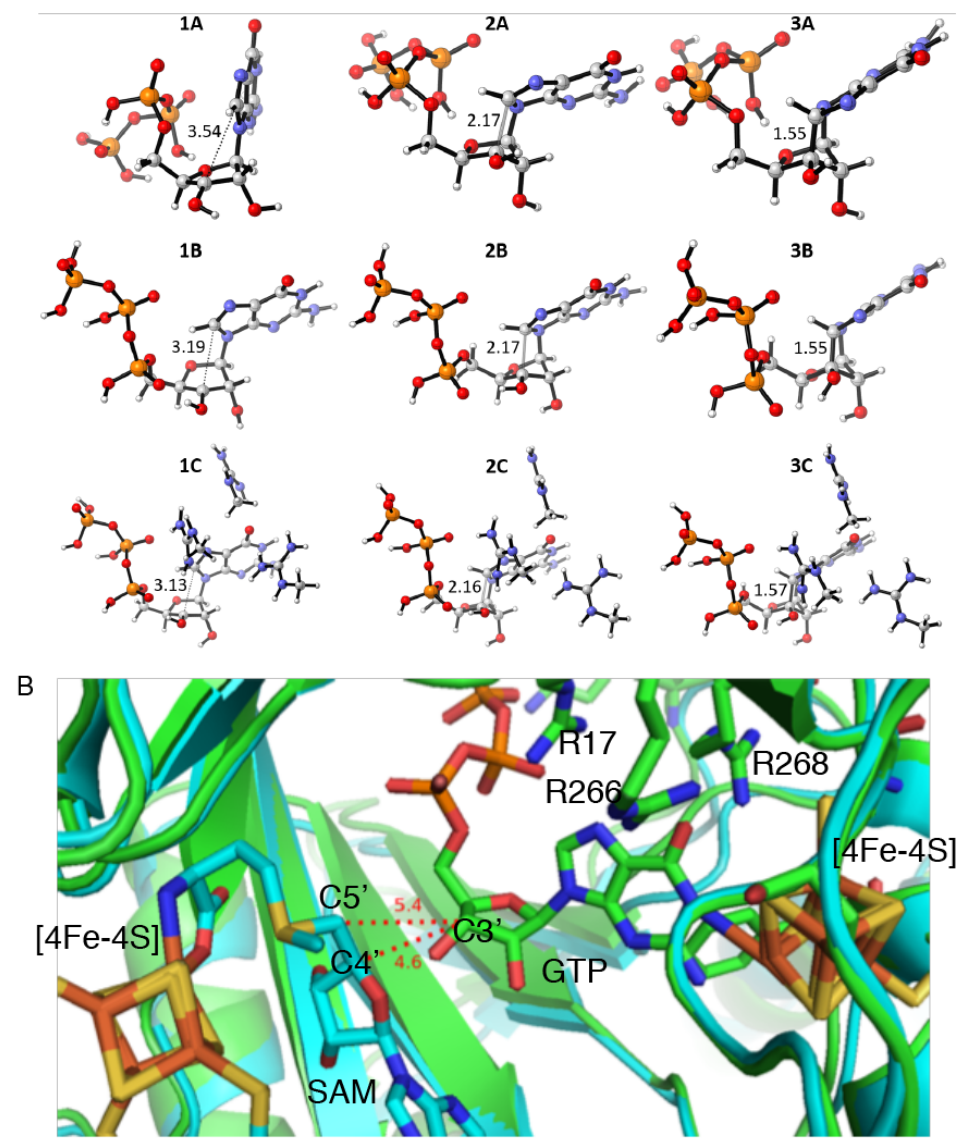

Figure 8. DFT calculation of 3',8-cyclization and model of MoaA active site. (A) Reaction coordinates of C3'-C8 bond formation from GTP-C3'• to yield 3',8-cyclo-GTP aminyl radical under three conditions: (1) in solution without any catalysis, (2) conformation constrained based on the crystal and solution structure of GTP bound to MoaA, (3) the conformationally constrained model (2) with three catalytically essential Arg residues. (B) Model of the MoaA active site is created by fusing the reported structure of MoaA in complex with SAM ${ }^{65}$ (PDB ID: 1TV8, cyan) and with GTP ${ }^{38}$ (PDB ID: 2FB3, green). Atom color: oxygens are shown in red, nitrogens in blue, phosphorus in orange, irons in brown, sulfurs in yellow. 


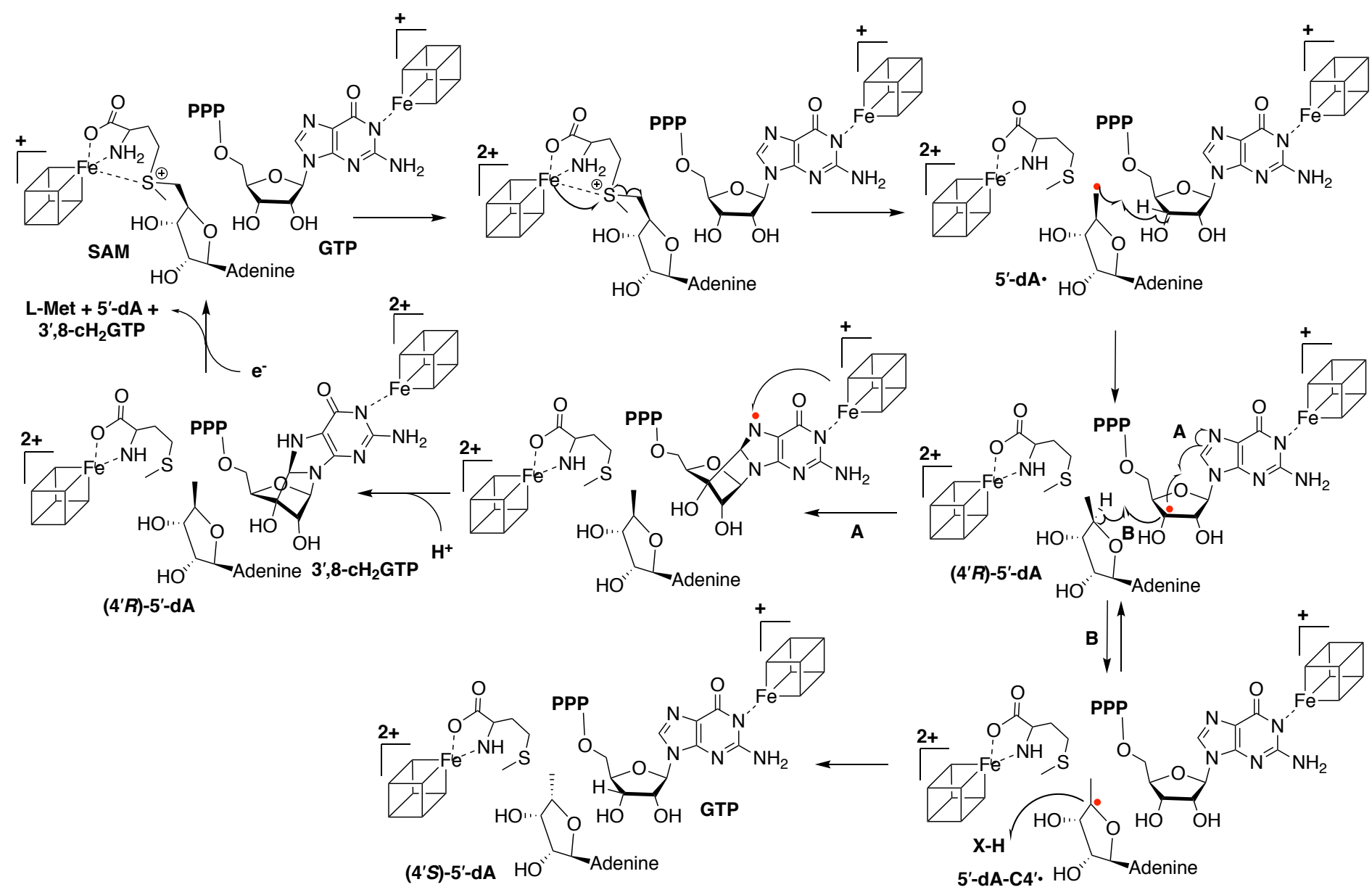

Figure 9. Mechanism of MoaA catalysis with the main pathway that yields $3^{\prime}, 8-\mathrm{CH}_{2} \mathrm{GTP}$ (path A), and the shunt pathway that produces (4'S)-5'-dA via 5'-dA-C4'• (path B). The cubes represent 4Fe-4S clusters. 
Table 1: The simulated $g$ values and ratio of the two axial signals from the reduced [4Fe-4S] clusters. Total amounts of reduced [4Fe-4S] clusters are quantified by EPR based on $1 \mathrm{mM} \mathrm{Cu}$ standard. Shown are averages of three replicates and the errors represent standard deviation.

\begin{tabular}{|c|c|c|c|c|c|c|c|c|}
\hline & \multirow[b]{2}{*}{ substrate } & \multicolumn{2}{|c|}{ species 1} & \multicolumn{2}{|c|}{ species 2} & \multirow[b]{2}{*}{ species $1 \%$} & \multirow[b]{2}{*}{ species $1: 2$} & \multirow{2}{*}{$\begin{array}{r}\text { total [4Fe-4S] } \\
\text { (eq. of MoaA) }\end{array}$} \\
\hline & & $g \perp$ & $g / /$ & $g \perp$ & $\mathrm{g} / /$ & & & \\
\hline \multirow{4}{*}{$\begin{array}{c}\mathrm{MoaA} \\
{[4 \mathrm{Fe}-4 \mathrm{~S}]^{+}}\end{array}$} & - & 1.897 & 2.031 & 1.875 & 2.063 & $57.4 \pm 1.5$ & $1.35 \pm 0.08$ & $0.94 \pm 0.09$ \\
\hline & SAM & 1.897 & 2.031 & 1.875 & 2.063 & $56.0 \pm 1.5$ & $1.28 \pm 0.08$ & $0.94 \pm 0.07$ \\
\hline & GTP & 1.890 & 2.029 & 1.881 & 2.063 & $23.1 \pm 1.0$ & $0.30 \pm 0.02$ & $1.11 \pm 0.06$ \\
\hline & GTP + SAM & 1.890 & 2.029 & 1.881 & 2.063 & $24.1 \pm 1.2$ & $0.32 \pm 0.02$ & $1.07 \pm 0.01$ \\
\hline
\end{tabular}


bioRxiv preprint doi: https://doi.org/10.1101/2020.01.16.909697; this version posted January 17, 2020. The copyright holder for this preprint (which was not certified by peer review) is the author/funder. All rights reserved. No reuse allowed without permission.

Table 2: The $g$ values and hyperfine tensors of all the simulated spectra of $5^{\prime}-\mathrm{dA}-\mathrm{C} 4^{\prime} \bullet$.

\begin{tabular}{|c|c|c|c|c|c|c|c|c|c|c|c|c|c|c|c|c|c|c|}
\hline Radical & GTP & SAM & $g_{\mathrm{xx}}$ & $g_{\mathrm{yy}}$ & $g_{\mathrm{zz}}$ & $A 1_{\mathrm{xx}}$ & $A 1_{\mathrm{yy}}$ & $A 1_{\mathrm{zz}}$ & $A 2_{\mathrm{xx}}$ & $A 2_{y y}$ & $A 2_{\mathrm{zz}}$ & $A 3_{\mathrm{xx}}$ & $A 3_{\mathrm{yy}}$ & $A 3_{\mathrm{zz}}$ & $A 4_{\mathrm{xx}}$ & $A 4_{\mathrm{yy}}$ & $A 4_{\mathrm{zz}}$ & Iwpp (mT) \\
\hline \multirow{5}{*}{$x$} & \multirow{5}{*}{ GTP } & SAM & 2.0059 & 2.0068 & 2.0092 & 72.1 & 66.6 & 57.6 & 43.7 & 66.1 & 113.6 & 64.1 & 21.3 & 111.3 & - & - & - & 1.07 \\
\hline & & {$\left[5^{\prime}-13 \mathrm{C}\right] \mathrm{SAM}$} & 2.0059 & 2.0068 & 2.0092 & 72.1 & 66.6 & 57.6 & 43.7 & 66.1 & 113.6 & 64.1 & 21.3 & 111.3 & 19.4 & 28.0 & 31.2 & 1.08 \\
\hline & & {$\left[5^{\prime}-{ }^{2} \mathrm{H}_{2}\right]$ SAM } & 2.0059 & 2.0068 & 2.0092 & 72.1 & 66.6 & 57.6 & 6.7 & 10.2 & 17.5 & 9.9 & 3.3 & 17.1 & - & - & - & 1.08 \\
\hline & & {$\left[4^{\prime}-13\right.$ C]SAM } & 2.0059 & 2.0068 & 2.0092 & 72.1 & 66.6 & 57.6 & 43.7 & 66.1 & 113.6 & 64.1 & 21.3 & 111.3 & 42.1 & 215.3 & 202.4 & 2.23 \\
\hline & & [ribose- ${ }^{13} \mathrm{C}_{5}$ ] SAM & 2.0059 & 2.0068 & 2.0092 & 72.1 & 66.6 & 57.6 & 43.7 & 66.1 & 113.6 & 64.1 & 21.3 & 111.3 & 42.1 & 215.3 & 202.4 & 2.19 \\
\hline \multirow{5}{*}{$Y$} & \multirow{5}{*}[3^{\prime}-{}^{2}\mathrm{H}]{$\mathrm{GTP}$} & SAM & 2.0059 & 2.0068 & 2.0092 & 11.1 & 10.2 & 8.9 & 43.7 & 66.1 & 113.6 & 64.1 & 21.3 & 111.3 & - & - & - & 1.08 \\
\hline & & {$\left[5^{\prime}-13 \mathrm{C}\right] \mathrm{SAM}$} & 2.0059 & 2.0068 & 2.0092 & 11.1 & 10.2 & 8.9 & 43.7 & 66.1 & 113.6 & 64.1 & 21.3 & 111.3 & 19.4 & 28.0 & 31.2 & 1.07 \\
\hline & & {$\left[5^{\prime}-{ }^{2} \mathrm{H}_{2}\right] \mathrm{SAM}$} & 2.0059 & 2.0068 & 2.0092 & 11.1 & 10.2 & 8.9 & 6.7 & 10.2 & 17.5 & 9.9 & 3.3 & 17.1 & - & - & - & 1.08 \\
\hline & & {$\left[4^{\prime}-{ }^{13} \mathrm{C}\right] \mathrm{SAM}$} & 2.0059 & 2.0068 & 2.0092 & 11.1 & 10.2 & 8.9 & 43.7 & 66.1 & 113.6 & 64.1 & 21.3 & 111.3 & 42.1 & 215.3 & 202.4 & 2.22 \\
\hline & & [ribose- ${ }^{-13} C_{5}$ ] SAM & 2.0059 & 2.0068 & 2.0092 & 11.1 & 10.2 & 8.9 & 43.7 & 66.1 & 113.6 & 64.1 & 21.3 & 111.3 & 42.1 & 215.3 & 202.4 & 2.23 \\
\hline
\end{tabular}


Table 3: Reported rate constants and activation energies for intramolecular cyclization reactions in solution.

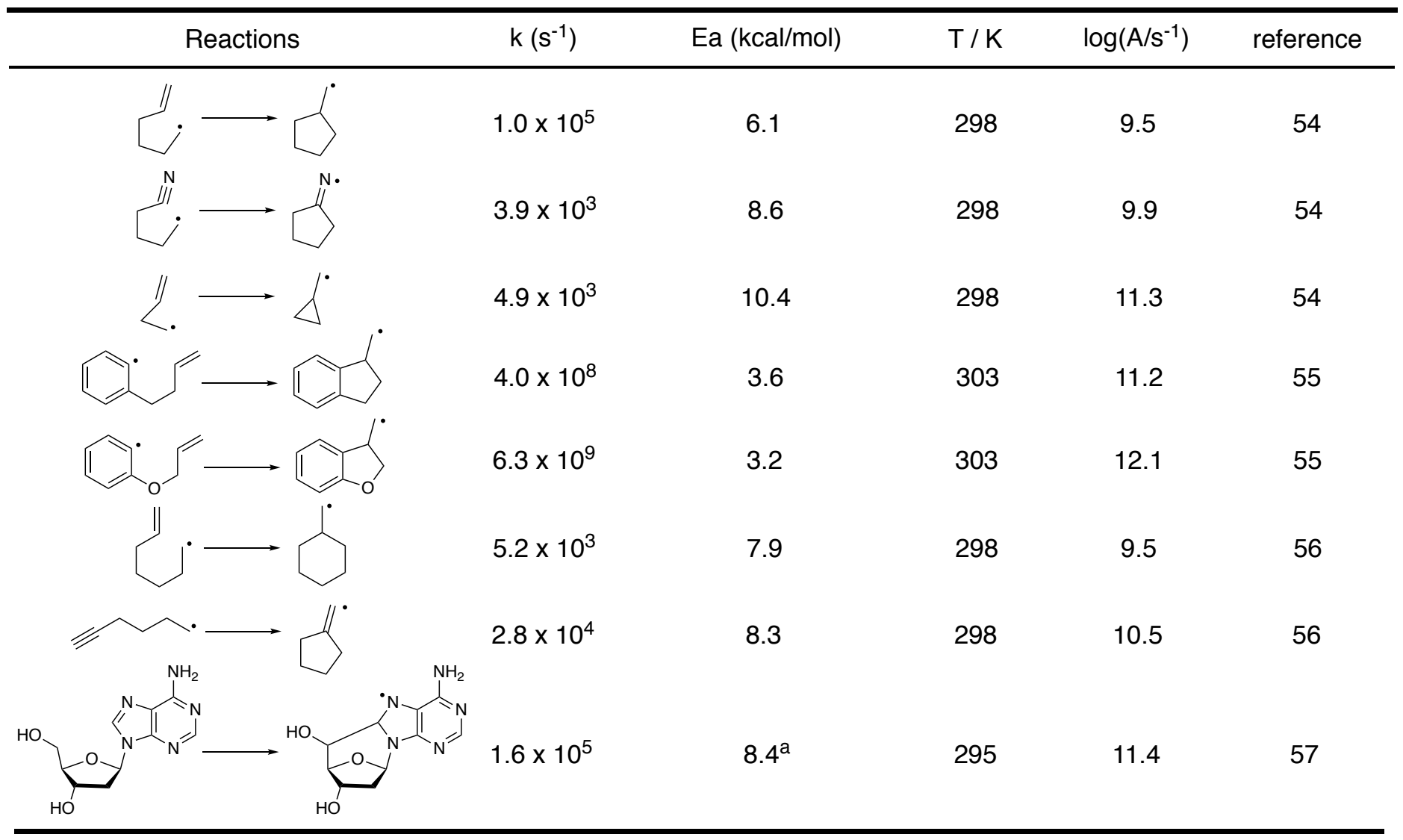

aActication energy based on DFT calculation 


\section{Methods:}

\section{General}

Sodium dithionite (SDT), L-methionine, 2-amino-6,7-dimethyl-4-hydroxypteridine (dimethylpterin, DMPT), 5'-deoxyadenosine (5'-dA), QAE Sephadex A-25 resin were purchased from Sigma-Aldrich, $\beta$-mercaptoethanol ( $\beta M E)$ from Calbiochem, dithiothreitol (DTT) from Amresco, Guanosine 5'-triphosphate (GTP) from Chem-Impex, Amberlite CG-50 resin from Fisher Scientific, G-25 Sephadex resin from GE Healthcare, Biogel-P2 size exclusion column from Bio-Rad, Ni-NTA agarose resin from Qiagen. [3'-2 ${ }^{2}$ ] GTP was enzymatically synthesized by Dr. Lincoln Scott at Cassia, LLC ${ }^{31-32}$. All the SAM with natural isotope abundance and ${ }^{2} \mathrm{H}$ or ${ }^{13} \mathrm{C}$ enrichment were enzymatically synthesized from L-methionine and ATP with appropriate isotope labels. Escherichia coli $(E$. coli) $\mathrm{DH} 5 \alpha$ and BL21(DE3) competent cells were from Invitrogen. Data plotting and nonlinear least-squares fitting was carried out using GraphPad Prism 7 software. All anaerobic experiments were carried out in an mBraun glovebox maintained at $10 \pm 2{ }^{\circ} \mathrm{C}$ with an $\mathrm{O}_{2}$ concentration $<0.1 \mathrm{ppm}$. All anaerobic buffers were degassed on a Schlenk line and equilibrated in the glovebox for overnight. All plastic devices were evacuated in the antechamber of glovebox for overnight before use. All HPLC experiments were performed on a Hitachi L-2130 pump equipped with an L-2455 diode array detector, an L-2485 fluorescence detector, an L-2200 autosampler, and an L-2300 column oven maintained at $40{ }^{\circ} \mathrm{C}$. XBridge Amide column (Waters) was used for SAM detection and ODS Hypersil C18 column (Thermo Scientific) for 5'-dA, DMPT, and compound Z. UV-vis absorption spectra were determined using the U-3900 UV-vis ratio recording double-beam spectrometer (Hitachi). EPR spectra were collected using an EMXplus 9.5/2.7 EPR spectrometer system equipped with an In-Cavity Cryo-Free VT system (Bruker Biospin Corporation). Simulation of EPR spectra were performed by EasySpin ${ }^{66}$. Kinetic fitting was performed by Global KinTek Explorer ${ }^{63-64}$. All MS spectra were recorded on a 6224 accurate-mass time-offlight mass spectrometer equipped with a Dual ESI source, and accurate mass data were obtained by internal calibration using a secondary nebulizer to continuously deliver the reference solution. Flow-injection analysis was conducted in full-scan mode using positive-ion polarity over the range of $80 \sim 1700 \mathrm{~m} / \mathrm{z}$. LCMS analysis was conducted on a PhenKinC18 EVO column $(3 \times 100 \mathrm{~mm})$ using formic acid in $\mathrm{H}_{2} \mathrm{O}$ /acetonitrile as mobile phase ( $0 \sim 100 \%$ acetonitrile within $10 \mathrm{~min}, 0.5 \mathrm{~mL} / \mathrm{min}$ ). NMR samples (isotopically labeled SAM) were prepared in 5 $\mathrm{mm}$ diameter NMR tubes with sealed capillary tube containing 0.05 wt. \% 3-(trimethylsilyl)propionic-2,2,3,3- $d_{4}$ acid, sodium salt in deuterium oxide (99.9 atom \% ${ }^{2} \mathrm{H}$ ). All NMR spectra were recorded on $700 \mathrm{MHz} B r u k e r$ Advance III NMR spectrometer operated with TopSpin NMR software and analyzed by SpinWorks 4.2.10.

\section{Expression and purification of recombinant MetK}

The plasmids for expression of E.coli MetK was kindly provided by Dr. Dewey McCafferty. MetK was heterologously expressed in E. coli BL21(DE3) cells harboring pET30b-MetK and a pLacl plasmid containing GroEL, GroES chaperon proteins from S. lividans ${ }^{67-69}$. Growths were carried out in the presence of kanamycin (35 mg/L) and chloramphenicol (25 mg/L). A single colony was picked and grown in LB medium (5 mL) for $8 \mathrm{hrs}$ followed by dilution into $250 \mathrm{~mL}$ LB in a $500 \mathrm{~mL}$ baffled flask incubated at $37{ }^{\circ} \mathrm{C}$ until the growth reaches saturation $(16 \mathrm{hrs})$. A portion $(40 \mathrm{~mL})$ of this culture was used to inoculate $1.5 \mathrm{~L}$ of $\mathrm{LB}$ medium in a $2.8 \mathrm{~L}$ baffled 
flask and grown at $37^{\circ} \mathrm{C}$ until an OD600 reaches $0.6 \sim 0.8$. MetK expression was induced by an addition of 0.25 mM IPTG. The culture continued for an additional $4 \mathrm{hrs}$. The cells were harvested by centrifugation, frozen in liquid nitrogen, and stored at $-80^{\circ} \mathrm{C}$. Typically, $5 \sim 6 \mathrm{~g}$ of wet cell pellet/L of culture were obtained.

Recombinant SAM synthetase, MetK, was aerobically purified. The cell pellets were resuspended and homogenized in 4 volumes of buffer $\mathrm{A}(50 \mathrm{mM}$ Tris $\cdot \mathrm{HCl}, \mathrm{pH} 7.6,0.3 \mathrm{M} \mathrm{NaCl}$ and $10 \%$ glycerol) supplemented with $3 \mathrm{mM} \beta \mathrm{ME}$. The cells were lysed by two passages through a French pressure cell operating at 14,000 psi. The resulting lysate was cleared by centrifugation at $25,000 \times g$ and $4{ }^{\circ} \mathrm{C}$ for $30 \mathrm{~min}$. The supernatant was loaded onto $20 \mathrm{~mL}$ Ni-NTA agarose resin equilibrated in buffer A supplemented with $3 \mathrm{mM} \beta M E$ and $20 \mathrm{mM}$ imidazole. Then the resin was washed with buffer A supplemented with $3 \mathrm{mM} \beta \mathrm{ME}$ and $20 \mathrm{mM}$ imidazole for 20 column volumes. MoaC was then eluted using buffer A supplemented with $3 \mathrm{mM} \beta \mathrm{ME}$ and $250 \mathrm{mM}$ imidazole. Fractions containing MetK, determined by SDS-PAGE, were exchanged into buffer B (50 mM Tris• HCl (pH 8.0$), 100 \mathrm{mM}$ $\mathrm{KCl}, 10 \mathrm{mM} \mathrm{MgCl}$, and $10 \%$ glycerol) using a Sephadex G-25 column. The concentration of MetK was determined based on the UV absorption at $280 \mathrm{~nm}$ using the extinction coefficients $\left(\varepsilon_{280 \mathrm{~nm}}=40.1 \mathrm{mM}^{-1} \cdot \mathrm{cm}^{-1}\right)$ as determined by Edelhoch's method.

\section{Enzymatic Synthesis of SAM isotopologues}

All natural isotope abundant and the isotopically enriched SAM ([ribose- $\left.{ }^{13} \mathrm{C}_{5}\right] \mathrm{SAM},\left[5^{\prime}-{ }^{13} \mathrm{C}\right] \mathrm{SAM}$, [5'$\left.{ }^{2} \mathrm{H}_{2}\right]$ SAM, and $\left[4^{\prime}-{ }^{13} \mathrm{C}\right] \mathrm{SAM}$ ) were prepared from (isotopically labeled) ATP and L-Met. The isotopically labeled ATP was enzymatically synthesized from isotopically labeled D-ribose or D-glucose using enzymes from de novo purine biosynthesis ${ }^{31-32}$. To enzymatically generate SAM from ATP and L-Met, $30 \mathrm{~mL}$ reaction containing $10 \mathrm{mM}$ isotope labeled ATP, $15 \mathrm{mM} \mathrm{L}-$ Met, $100 \mathrm{mM}$ Tris $\bullet \mathrm{HCl}(\mathrm{pH} 8.0), 50 \mathrm{mM} \mathrm{KCl}, 30 \mathrm{mM} \mathrm{MgCl}, 8 \% \beta M E$ and $3 \mathrm{mg} / \mathrm{mL}$ MetK was incubated at room temperature and progress was monitored by HPLC. The reaction typically yielded approximately $60 \%$ conversion (based on the starting concentration of ATP) after $4 \mathrm{~h}$ incubation. The reaction was quenched by adjusting the $\mathrm{pH}$ to 5 by adding $\mathrm{HCl}$.

Purification of SAM was based on the previous report ${ }^{68}$. The quenched reaction mixture was cleared by centrifugation, and the supernatant was then loaded onto $100 \mathrm{~mL}$ of weak cation exchange resin (Amberlite CG50) equilibrated with $1 \mathrm{mM}$ sodium acetate $\mathrm{pH} 5$ buffer. The column was washed with the same buffer for 5 column volumes (CV) and then SAM was eluted using $40 \mathrm{mM} \mathrm{H}_{2} \mathrm{SO}_{4}$. Fractions containing SAM determined by UV and HPLC were pooled and titrated with QAE Sephadex A-25 resin in hydroxide form to $\mathrm{pH}$ 5. The resultant solution was then concentrated by rotary evaporation to less than $3 \mathrm{~mL}$, and loaded onto a $150 \mathrm{~mL}$ Bio-Rad Biogel-P2 size exclusion column equilibrated in $\mathrm{H}_{2} \mathrm{O}$. SAM was eluted with $\mathrm{H}_{2} \mathrm{O}$ after $2 \mathrm{CV}$. Fractions containing SAM determined by UV and HPLC were pooled and concentrated by rotary evaporation to less than $3 \mathrm{~mL}$. This solution was degassed and transferred into glovebox for anaerobic assays. The compounds were characterized by MS and NMR and stored at $-35^{\circ} \mathrm{C}$ in the glovebox. This method generally yields SAM with $>96 \%$ purity (analyzed by HPLC) and a total yield of $\sim 25 \%$ based on ATP.

\section{X-band CW-EPR experiments}


MoaA assays were carried out under strict anaerobic condition (<0.1 ppm $\left.\mathrm{O}_{2}\right)$. MoaA $(450 \mu \mathrm{M})$ was first pre-reduced by $1.5 \mathrm{mM}$ sodium dithionite (SDT) in buffer $\mathrm{A}(100 \mathrm{mM}$ Tris $\bullet \mathrm{HCl}(\mathrm{pH} 7.6), 0.3 \mathrm{M} \mathrm{NaCl}, 10 \%$ glycerol, $5 \mathrm{mM} \mathrm{DTT}$ ) at $25^{\circ} \mathrm{C}$ for $60 \mathrm{~min}$. To initiate the reaction, the pre-reduced MoaA was then mixed with SAM and GTP in buffer A. The final concentration of each component was $300 \mu \mathrm{M}$ MoaA, $1 \mathrm{mM}$ SDT, 1 mM SAM (or isotopologues) and $1 \mathrm{mM}$ GTP or $\left[3^{\prime}-{ }^{2} \mathrm{H}\right] \mathrm{GTP}$. For the EPR experiments with $\left[4^{\prime}-{ }^{13} \mathrm{C}\right] \mathrm{SAM}$ or $\left[\right.$ ribose- $\left.{ }^{13} \mathrm{C}_{5}\right] \mathrm{SAM}$, $500 \mu \mathrm{M}$ MoaA was used to improve the signal-to-noise ratio. The samples were transferred into EPR tubes and freeze-quenched manually by submerging in isopentane slush bath $(\sim 110 \mathrm{~K})$ in the glovebox. The samples were then taken out of the glovebox and kept in liquid nitrogen for X-band continuous wave EPR characterization.

The EPR spectrum for the [4Fe-4S] clusters were determined at $15 \mathrm{~K}$. EPR parameters were a microwave frequency of $9.36 \sim 9.39 \mathrm{GHz}$; a power of $1.589 \mathrm{~mW}$; modulation amplitude of $10 \mathrm{G}$; modulation frequencies of $100 \mathrm{kHz}$; time constants of $0.01 \mathrm{~ms}$ and a scan time of $100 \mathrm{~s}$. Quantitation of the [4Fe-4S] cluster signal was carried out using a $1 \mathrm{mM} \mathrm{Cu}$ (II) sample as standard. The $\mathrm{Cu}$ (II) standard was prepared from a $\sim 100 \mathrm{mM} \mathrm{CuSO}_{4}$ stock solution in $\mathrm{H}_{2} \mathrm{O}$ with the $\mathrm{Cu}(\mathrm{II})$ concentration determined by light absorbance at $810 \mathrm{~nm}\left(\varepsilon_{810 \mathrm{~nm}}=11.8 \mathrm{M}^{-}\right.$ $\left.{ }^{1} \cdot \mathrm{cm}^{-1}\right)$. The stock solution was diluted in $2 \mathrm{M} \mathrm{NaClO}_{4}, 10 \mathrm{mM} \mathrm{HCl}, 20 \%$ glycerol to prepare $1 \mathrm{mM} \mathrm{CuSO} 4$. EPR spectra of $\mathrm{Cu}(\mathrm{II})$ standard were determined under following conditions: A microwave frequency of 9.36 9.39 $\mathrm{GHz}$; a power of $0.02 \mathrm{~mW}$; modulation amplitude of $4 \mathrm{G}$; modulation frequencies of $60 \mathrm{kHz}$; time constants of $0.04 \mathrm{~ms}$ and a scan time of $30 \mathrm{~s}$.

The EPR spectra of the organic radical with non-labeled or isotopically labeled substrates were all determined at $45 \mathrm{~K}$, with a microwave frequency of $9.36 \sim 9.39 \mathrm{GHz}$; a power of $12.62 \mathrm{~mW}$; modulation amplitude of $2 \mathrm{G}$; modulation frequencies of $100 \mathrm{kHz}$; time constants of $0.01 \mathrm{~ms}$ and a scan time of $70 \mathrm{~s}$. Quantitation of the organic radical signal was carried out using a $18.0 \mu \mathrm{M}$ flavosemiquinone radical (Flv•) as standard. Flv• was prepared as previously reported ${ }^{33-34} .1 .05$ eq. of flavodoxin was incubated with 0.5 eq. of SDT at $37^{\circ} \mathrm{C}$ for 60 min under anaerobic condition. The concentration of Flv• was determined based on the light absorbance at 579 $\mathrm{nm}\left(\varepsilon_{579 \mathrm{~nm}}=4570 \mathrm{M}^{-1} \cdot \mathrm{cm}^{-1}\right)$. The sample was then transferred into EPR tube and frozen in an isopentane slush bath. EPR parameters for Flv• standard were a microwave frequency of $9.36 \sim 9.39 \mathrm{GHz}$; a power of 0.3991 $\mu \mathrm{W}$; modulation amplitude of $10 \mathrm{G}$; modulation frequencies of $100 \mathrm{kHz}$; time constants of $0.01 \mathrm{~ms}$ and a scan time of $50 \mathrm{~s}$.

The recorded EPR spectrum was first processed by a baseline correction using Xenon software. For the EPR spectrum of organic radical species, the signal from [4Fe-4S] cluster was subtracted by a control reaction without SAM. The observed signal intensity was determined by calculating the double integration of the first derivative EPR spectrum. This observed intensity was then normalized by the following equation:

$$
\text { normalized intensity }(\mathrm{DI} / \mathrm{Nc})=\frac{\text { Observed intensity }(\mathrm{DI})}{M \cdot g \cdot f \cdot \sqrt{P}}
$$

$M$ represents modulation amplitude, $P$ is the microwave power, $g$ is the average $g$ value of the radical, $f$ is a packing factor related to the inner diameter of EPR tube. The normalized intensity was compared to that of $\mathrm{Cu}$ (II) standard to get the exact spin concentration of the sample. All EPR spectral simulations were performed using the EasySpin software ${ }^{66}$. 


\section{Quantitation of (4'R)-5'-dA, (4'S)-5'-dA and 3',8-cH ${ }_{2}$ GTP by MoaA/MoaC coupled assay}

MoaA/MoaC coupled assay was carried out to study the kinetics of the MoaA-catalyzed reaction. MoaA $(300 \mu \mathrm{M})$ was incubated with MoaC $(300 \mu \mathrm{M})$, GTP $(1 \mathrm{mM})$, SAM $(1 \mathrm{mM})$, SDT $(1 \mathrm{mM})$ in buffer B (100 mM Tris $\bullet \mathrm{HCl}$ (pH 7.6), 0.3 M NaCl, $10 \%$ glycerol, $\left.1 \mathrm{mM} \mathrm{MgCl}_{2}, 5 \mathrm{mM} \mathrm{DTT}\right)$. MoaA was first incubated with SDT and MoaC at $25^{\circ} \mathrm{C}$ for 30 min to pre-reduce MoaA and transform all the co-purified 3 ',8- $\mathrm{cH}_{2} \mathrm{GTP}$ to cPMP. Reaction was then initiated by mixing with GTP and SAM in buffer B. A $30 \mu \mathrm{L}$ aliquot of the reaction was quenched with $120 \mu \mathrm{L} 3 \%(\mathrm{w} / \mathrm{v})$ trichloroacetic acid (TCA) at each time point. The quenched sample was centrifuged at 16,100 $x \mathrm{~g}$ for 10 min to remove protein precipitation. To derivatize cPMP into compound $\mathrm{Z}(\mathrm{CmdZ})^{14}$, a solution $(25 \mu \mathrm{L})$ containing $0.2 \%(\mathrm{w} / \mathrm{v}) \mathrm{I}_{2}$ and $0.4 \%(\mathrm{w} / \mathrm{v}) \mathrm{KI}$ was mixed with $25 \mu \mathrm{L}$ of the cleared reaction mixture followed by incubation at room temperature for $20 \mathrm{~min}$. The sample was then diluted with mobile phase $\left(0.1 \%\right.$ TFA in $\left.\mathrm{H}_{2} \mathrm{O}\right)$, centrifuged to remove any precipitant, and injected onto the HPLC equipped with an ODS Hypersil column (4.6 x $250 \mathrm{~mm})$. Chromatography was performed by an isocratic elution with $0.1 \% \mathrm{TFA}$ in $\mathrm{H}_{2} \mathrm{O}(0.8 \mathrm{~mL} / \mathrm{min}, 15 \mathrm{~min}$, retention time: $5.5 \mathrm{~min}$ ) and monitored by fluorescence (excitation: $367 \mathrm{~nm}$, emission: $450 \mathrm{~nm}$ ). The concentration of $\mathrm{CmdZ}$ was quantified based on the standard curve from authentic $\mathrm{CmdZ}$ standard. $\mathrm{CmdZ}$ standard was prepared by following reported protocol ${ }^{70}$. To quantify the residual unconverted 3 ',8- $\mathrm{cH}_{2} \mathrm{GTP}$, an aliquot of $50 \mu \mathrm{L}$ quenched sample was chemically derivatized to DMPT by following a previous published method ${ }^{14}$. The quenched mixture $(30 \mu \mathrm{L})$ was incubated at $95^{\circ} \mathrm{C}$ for $5 \mathrm{~min}$ to completely hydrolyze MoaA product and release the 6-hydroxy-2,4,5-triaminopyrimidine moiety. After cooling down, the sample was neutralized by $5 \mu \mathrm{L} 0.75 \mathrm{M} \mathrm{NaOH}$ and mixed with $15 \mu \mathrm{L}$ of $0.66 \%(\mathrm{v} / \mathrm{v})$ 2,3-butanedione in $0.9 \mathrm{M} \mathrm{Tris} \bullet \mathrm{HCl}(\mathrm{pH} 8.5)$. The solution was incubated at $95^{\circ} \mathrm{C}$ for $45 \mathrm{~min}$. The resultant solution was then diluted with mobile phase (30 mM ammonium formate, $\mathrm{pH} 4.5$ ), centrifuged to remove any precipitant, and injected onto the HPLC equipped with an ODS Hypersil column (4.6 x $150 \mathrm{~mm}$ ). Chromatography was performed by an isocratic elution with $7.5 \% \mathrm{MeOH}, 92.5 \%$ $30 \mathrm{mM}$ ammonium formate, $\mathrm{pH} 4.5$ (22.5 min, $1 \mathrm{~mL} / \mathrm{min}$, retention time: $11.5 \mathrm{~min}$ ) and monitored by fluorescence (excitation $365 \mathrm{~nm}$, emission $445 \mathrm{~nm}$ ). The concentration of DMPT was quantified based on the standard curve of commercial DMPT standard. The amount of $3^{\prime}, 8-\mathrm{cH}_{2} \mathrm{GTP}$ was calculated as a sum of CmdZ and DMPT. The amount of co-purified 3',8- $\mathrm{CH}_{2}$ GTP was subtracted by a MoaA/MoaC reaction with all the components except SAM analyzed by the same protocol. The remaining $\sim 75 \mu \mathrm{L}$ quenched sample was used for $\left(4^{\prime} R\right)-5^{\prime}-\mathrm{dA}$ and (4'S)-5'-dA. After removal of precipitation, the quenched sample was directly injected onto the HPLC equipped with an ODS Hypersil column (4.6 x $150 \mathrm{~mm})$. Chromatography was performed by a linear gradient of $0 \sim 20 \%$ $\mathrm{MeOH}$ in $30 \mathrm{mM}$ ammonium formate, $\mathrm{pH} 4.5$ (18 min, $1 \mathrm{~mL} / \mathrm{min}$, retention time: $12.7 \mathrm{~min}$ for (4'S)-5'-dA, 14.6 min for (4'R)-5'-dA) and monitored by UV absorption at $260 \mathrm{~nm}$. The concentration of both (4'R)-5'-dA and (4'S)$5^{\prime}-\mathrm{dA}$ were quantified based on the standard curve of 5'-dA.

\section{DFT calculation}




\section{References:}

1. Sofia, H. J.; Chen, G.; Hetzler, B. G.; Reyes-Spindola, J. F.; Miller, N. E., Radical SAM, a novel protein superfamily linking unresolved steps in familiar biosynthetic pathways with radical mechanisms- functional characterization using new analysis and information visualization methods. Nucleic acids research 2001, 29 (5), 1097-1106.

2. Frey, P. A.; Hegeman, A. D.; Ruzicka, F. J., The Radical SAM Superfamily. Crit Rev Biochem Mol Biol 2008, 43 (1), 63-88.

3. Shisler, K. A.; Broderick, J. B., Emerging themes in radical SAM chemistry. Curr Opin Struct Biol 2012, 22 (6), 701-10.

4. Hille, R.; Nishino, T.; Bittner, F., Molybdenum enzymes in higher organisms. Coord Chem Rev 2011, 255 (9-10), 1179-1205.

5. Hille, R., The mononuclear molybdenum enzymes. Chem Rev 1996, 96 (7), 2757-2816.

6. Mendel, R. R.; Schwarz, G., Molybdenum cofactor biosynthesis in plants and humans. Coordination chemistry reviews 2011, 255, 1145-1158.

7. lobbi-Nivol, C.; Leimkuhler, S., Molybdenum enzymes, their maturation and molybdenum cofactor biosynthesis in Escherichia coli. Biochim Biophys Acta 2012.

8. Schwarz, G.; Mendel, R. R.; Ribbe, M. W., Molybdenum cofactors, enzymes and pathways. Nature (London, U. K.) 2009, 460 (7257), 839-847.

9. Warnhoff, K.; Ruvkun, G., Molybdenum cofactor transfer from bacteria to nematode mediates sulfite detoxification. Nat Chem Biol 2019, 15 (5), 480-488.

10. Johnson, J. L.; Waud, W. R.; Rajagopalan, K. V.; Duran, M.; Beemer, F. A.; Wadman, S. K., Inborn errors of molybdenum metabolism: combined deficiencies of sulfite oxidase and xanthine dehydrogenase in a patient lacking the molybdenum cofactor. P Natl Acad Sci USA 1980, 77 (6), 3715-9.

11. Boshoff, H. I.; Barry, C. E., 3rd, Tuberculosis-metabolism and respiration in the absence of growth. Nat Rev Microbiol 2005, 3 (1), 70-80.

12. Folkesson, A.; Jelsbak, L.; Yang, L.; Johansen, H. K.; Ciofu, O.; Hoiby, N.; Molin, S., Adaptation of Pseudomonas aeruginosa to the cystic fibrosis airway: an evolutionary perspective. Nat Rev Microbiol 2012, 10 (12), 841-51.

13. Leimkuhler, S.; Wuebbens, M. M.; Rajagopalan, K. V., The History of the Discovery of the Molybdenum Cofactor and Novel Aspects of its Biosynthesis in Bacteria. Coordination chemistry reviews 2011, 255 (9-10), 1129-1144.

14. Hover, B. M.; Loksztejn, A.; Ribeiro, A. A.; Yokoyama, K., Identification of a cyclic nucleotide as a cryptic intermediate in molybdenum cofactor biosynthesis. J Am Chem Soc 2013, 135 (18), 7019-32.

15. Hover, B. M.; Tonthat, N. K.; Schumacher, M. A.; Yokoyama, K., Mechanism of pyranopterin ring formation in molybdenum cofactor biosynthesis. Proc Natl Acad Sci U S A 2015, 112 (20), 6347-52.

16. Licht, S.; Gerfen, G. J.; Stubbe, J., Thiyl radicals in ribonucleotide reductases. Science 1996, 271 (5248), 477-481.

17. Olshansky, L.; Pizano, A. A.; Wei, Y.; Stubbe, J.; Nocera, D. G., Kinetics of hydrogen atom abstraction from substrate by an active site thiyl radical in ribonucleotide reductase. J Am Chem Soc 2014, 136 (46), $16210-16216$.

18. Wei, Y.; Mathies, G.; Yokoyama, K.; Chen, J.; Griffin, R. G.; Stubbe, J., A Chemically Competent Thiosulfuranyl Radical on the Escherichia coli Class III Ribonucleotide Reductase. J Am Chem Soc 2014, 136 (25), 9001-9013.

19. Donk, W. A. v. d.; Zeng, C.; Biemann, K.; Stubbe, J., Identification of an active site residue of the R1 subunit of ribonucleotide reductase from Escherichia coli: characterization of substrate-induced polypeptide cleavage by C225SR1. Biochemistry 1996, 35 (31), 10058-10067.

20. Lawrence, C. C.; Bennati, M.; Obias, H. V.; Bar, G.; Griffin, R. G.; Stubbe, J., High-field EPR detection of a disulfide radical anion in the reduction of cytidine 5. Proc Natl Acad Sci U S A 1999, 96 (16), 8979-8984.

21. Stubbe, J.; Donk, W. A. V. D., Ribonucleotide reductases: radical enzymes with suicidal tendencies. Chemistry \& biology 1995, 2 (12), 793-801.

22. Lahoud, G. A.; Hitt, A. L.; Bryant-Friedrich, A. C., Aerobic Fate of the C-3'-Thymidinyl Radical in SingleStranded DNA. Chemical research in toxicology 2006, 19 (12), 1630-1636. 
23. Chen-Barrett, Y.; Harrison, P. M.; Treffry, A.; Quail, M. A.; Arosio, P.; Santambrogio, P.; Chasteen, N. D., Tyrosyl radical formation during the oxidative deposition of iron in human apoferritin. Biochemistry 1995, 34 (24), 7847-7853.

24. Sahlin, M.; Gräslund, A.; Ehrenberg, A., Determination of relaxation times for a free radical from microwave saturation studies. Journal of Magnetic Resonance (1969) 1986, 67 (1), 135-137.

25. Lilla, E. A.; Yokoyama, K., Carbon extension in peptidylnucleoside biosynthesis by radical SAM enzymes. Nature chemical biology 2016, 12 (11), 905-907.

26. Grove, T. L.; Livada, J.; Schwalm, E. L.; Green, M. T.; Booker, S. J.; Silakov, A., A substrate radical intermediate in catalysis by the antibiotic resistance protein Cfr. Nature chemical biology 2013, 9 (7), 422.

27. Yokoyama, K.; Ohmori, D.; Kudo, F.; Eguchi, T., Mechanistic study on the reaction of a radical SAM dehydrogenase BtrN by electron paramagnetic resonance spectroscopy. Biochemistry 2008, 47 (34), $8950-$ 8960.

28. Grove, T. L.; Ahlum, J. H.; Sharma, P.; Krebs, C.; Booker, S. J., A consensus mechanism for Radical SAM-dependent dehydrogenation? BtrN contains two [4Fe-4S] clusters. Biochemistry 2010, 49 (18), $3783-5$. 29. Ballinger, M. D.; Reed, G. H.; Frey, P. A., An organic radical in the lysine 2,3-aminomutase reaction. Biochemistry 1992, 31 (4), 949-953.

30. Ballinger, M. D.; Frey, P. A.; Reed, G. H., Structure of a substrate radical intermediate in the reaction of lysine 2, 3-aminomutase. . Biochemistry 1992, 31 (44), 10782-10789.

31. Tolbert, T. J.; Williamson, J. R., Preparation of specifically deuterated RNA for NMR studies using a combination of chemical and enzymatic synthesis. J Am Chem Soc 1996, 118 (34), 7929-7940.

32. Schultheisz, H. L.; Szymczyna, B. R.; Scott, L. G.; Williamson, J. R., Pathway engineered enzymatic de novo purine nucleotide synthesis. ACS chemical biology 2008, 3 (8), 499-511.

33. Silakov, A.; Grove, T. L.; Radle, M. I.; Bauerle, M. R.; Green, M. T.; Rosenzweig, A. C.; Boal, A. K.; Booker, S. J., Characterization of a Cross-Linked Protein-Nucleic Acid Substrate Radical in the Reaction Catalyzed by RImN. J Am Chem Soc 2014, 136 (23), 8221-8228.

34. Lanz, N. D.; Grove, T. L.; Gogonea, C. B.; Lee, K. H.; Krebs, C.; Booker, S. J.; In Methods in enzymology (Vol. 516, p.-A. P., Chapter Seven - RImN and AtsB as models for the overproduction and characterization of radical SAM proteins. Methods Enzymol 2012, 516, 125-152.

35. Wuebbens, M. M.; Rajagopalan, K. V., Investigation of the early steps of molybdopterin biosynthesis in Escherichia coli through the use of in vivo labeling studies. J Biol Chem 1995, 270 (3), 1082-7.

36. Storer, A. C.; Cornish-Bowden, A., The kinetics of coupled enzyme reactions. Applications to the assay of glucokinase, with glucose 6-phosphate dehydrogenase as coupling enzyme. Biochemical Journal 1974, 141 (1), 205-209.

37. Copeland, R. A., Enzymes: A Practical Introduction to Structure, Mechanism, and Data Analysis. Copyright @ 2000 by Wiley - VCH, Inc. 2000, Second Edition, 188-193.

38. Hänzelmann, P.; Schindelin, H., Binding of 5'-GTP to the C-terminal FeS cluster of the radical Sadenosylmethionine enzyme MoaA provides insights into its mechanism. P Natl Acad Sci USA 2006, 103 (18), 6829-34.

39. Baraniak, J.; Moss, M. L.; Frey, P. A., Lysine 2, 3-aminomutase. Support for a mechanism of hydrogen transfer involving S-adenosylmethionine. J Biol Chem 1989, 264 (3), 1357-1360.

40. Yokoyama, K.; Ohmori, D.; Kudo, F.; Eguchi, T., Mechanistic study on the reaction of a radical SAM dehydrogenase BtrN by electron paramagnetic resonance spectroscopy. Biochemistry 2008, 47 (34), $8950-60$. 41. Duffus, B. R.; Ghose, S.; Peters, J. W.; Broderick, J. B., Reversible H Atom Abstraction Catalyzed by the Radical S-Adenosylmethionine Enzyme HydG. J Am Chem Soc 2014, 136 (38), 13086-13089.

42. Griller, D.; Ingold, K. U., Free-radical clocks. Accounts of Chemical Research 1980, 13 (9), $317-323$. 43. Johnston, L. J.; Lusztyk, J.; Wayner, D. D. M.; Abeywickreyma, A. N.; Beckwith, A. L. J.; Scaiano, J. C.; Ingold, K. U., Absolute rate constants for reaction of phenyl, 2, 2-dimethylvinyl, cyclopropyl, and neopentyl radicals with tri-n-butylstannane. Comparison of the radical trapping abilities of tri-n-butylstannane and germane. J Am Chem Soc 1985, 107 (15), 4594-4596.

44. Beckwith, A. L.; Schiesser, C. H., A force-field study of alkenyl radical ring closure. Tetrahedron letters 1985, 26 (3), 373-376.

45. Chatgilialoglu, C.; Guerra, M.; Mulazzani, Q. G., Model studies of DNA C5' radicals. Selective generation and reactivity of 2'-deoxyadenosin-5'-yl radical. J Am Chem Soc 2003, 125 (13), 3839-3848. 46. Lees, N. S.; Hänzelmann, P.; Hernandez, H. L.; Subramanian, S.; Schindelin, H.; Johnson, M. K.; Hoffman, B. M., ENDOR spectroscopy shows that guanine N1 binds to [4Fe-4S] cluster II of the S- 
adenosylmethionine-dependent enzyme MoaA: mechanistic implications. J Am Chem Soc 2009, 131 (26), 9184-5.

47. Szu, P. H.; Ruszczycky, M. W.; Choi, S. H.; Yan, F.; Liu, H. W., Characterization and mechanistic studies of Desll: a radical S-adenosyl-L-methionine enzyme involved in the biosynthesis of TDP-D-

desosamine. J Am Chem Soc 2009, 131 (39), 14030-14042.

48. Ruszczycky, M. W.; Ogasawara, Y.; Liu, H. W., Radical SAM enzymes in the biosynthesis of sugarcontaining natural products. Biochim Biophys Acta 2012, 1824 (11), 1231-1244.

49. Bridwell-Rabb, J.; Drennan, C. L., A radically unexpected mechanism. Science 2016, 351 (6279), 12661267.

50. Sicoli, G.; Mouesca, J. M.; Zeppieri, L.; Amara, P.; Martin, L.; Barra, A. L.; Fontecilla-Camps, J. C.; Gambarelli, S.; Nicolet, Y.; 2016. Fine-tuning of a radical-based reaction by radical S-adenosyl-L-methionine tryptophan lyase. Science, pp.1320-1323., Fine-tuning of a radical-based reaction by radical S-adenosyl-Lmethionine tryptophan lyase. Science 2016, 351 (6279), 1320-1323.

51. Ji, X.; Li, Y.; Ding, W.; Zhang, Q., Substrate - Tuned Catalysis of the Radical S - Adenosyl - L Methionine Enzyme NosL Involved in Nosiheptide Biosynthesis. Angewandte Chemie International Edition 2015, 54 (31), 9021-9024.

52. Bhandari, D. M.; Xu, H.; Nicolet, Y.; Fontecilla-Camps, J. C.; Begley, T. P., Tryptophan lyase (NosL): mechanistic insights from substrate analogues and mutagenesis. Biochemistry 2015, 54 (31), 4767-4769. 53. Zhang, Q.; Li, Y.; Chen, D.; Yu, Y.; Duan, L.; Shen, B.; Liu, W., Radical-mediated enzymatic carbon chain fragmentation-recombination. Nature chemical biology 2011, 7 (3), 154-160.

54. Hover, B. M.; Yokoyama, K., C-Terminal glycine-gated radical initiation by GTP 3',8-cyclase in the molybdenum cofactor biosynthesis. J Am Chem Soc 2015, 137 (9), 3352-9.

55. Goldman, P. J.; Grove, T. L.; Booker, S. J.; Drennan, C. L., X-ray analysis of butirosin biosynthetic enzyme BtrN redefines structural motifs for AdoMet radical chemistry. P Natl Acad Sci USA 2013, 110 (40), $15949-15954$.

56. Guilford, W. J.; Copley, S. D.; Knowles, J. R., On the Mechanism of the Chorismate Mutase Reaction. J Am Chem Soc 1987, 109 (16), 5013-5019.

57. Hur, S.; Bruice, T. C., The near attack conformation approach to the study of the chorismate to prephenate reaction. $P$ Natl Acad Sci USA 2003, 100 (21), 12015-12020.

58. Jackson, D. Y.; Liang, M. N.; Bartlett, P. A.; Schultz, P. G., Activation Parameters and Stereochemistry of an Antibody-Catalyzed Claisen Rearrangement. Angew Chem Int Edit 1992, 31 (2), 182-183.

59. Kienhofer, A.; Kast, P.; Hilvert, D., Selective stabilization of the chorismate mutase transition state by a positively charged hydrogen bond donor. J Am Chem Soc 2003, 125 (11), 3206-3207.

60. Holliday, G. L.; Akiva, E.; Meng, E. C.; Brown, S. D.; Calhoun, S.; Pieper, U.; Sali, A.; Booker, S. J.; Babbitt, P. C., Atlas of the radical SAM superfamily: Divergent evolution of function using a "Plug and Play" domain. Methods Enzymol 2018, 606, 1-71.

61. Maiocco, S. J.; Grove, T. L.; Booker, S. J.; Elliott, S. J., Electrochemical Resolution of the [4Fe-4S] Centers of the AdoMet Radical Enzyme BtrN: Evidence of Proton Coupling and an Unusual, Low-Potential Auxiliary Cluster. J Am Chem Soc 2015, 137, 8664-8667.

62. Yokoyama, K.; Lilla, E. A., C-C bond forming radical SAM enzymes involved in the construction of carbon skeletons of cofactors and natural products. Nat. Prod. Rep. 2018, Publish online.

63. Johnson, K. A.; Simpson, Z. B.; Blom, T., Global kinetic explorer: a new computer program for dynamic simulation and fitting of kinetic data. Analytical biochemistry 2009, 387 (1), 20-29.

64. Johnson, K. A.; Simpson, Z. B.; Blom, T., FitSpace explorer: an algorithm to evaluate multidimensional parameter space in fitting kinetic data. Analytical biochemistry 2009, 387 (1), 30-41.

65. Hänzelmann, P.; Schindelin, H., Crystal structure of the S-adenosylmethionine-dependent enzyme MoaA and its implications for molybdenum cofactor deficiency in humans. P Natl Acad Sci USA 2004, 101 (35), 12870-5.

66. Stoll, S.; Schweiger, A., EasySpin, a comprehensive software package for spectral simulation and analysis in EPR. Journal of magnetic resonance 2006, 178 (1), 42-55.

67. Kerner, M. J.; Naylor, D. J.; Ishihama, Y.; Maier, T.; Chang, H. C.; Stines, A. P.; Georgopoulos, C.; Frishman, D.; Hayer-Hartl, M.; Mann, M.; Hartl, F. U., Proteome-wide analysis of chaperonin-dependent protein folding in Escherichia coli. Cell 2005, 122 (2), 209-220.

68. Iwig, D. F.; Booker, S. J., Insight into the Polar Reactivity of the Onium Chalcogen Analogues of SAdenosyl-I-methionine. Biochemistry 2004, 43 (42), 13496-13509. 
bioRxiv preprint doi: https://doi.org/10.1101/2020.01.16.909697; this version posted January 17, 2020. The copyright holder for this preprint (which was not certified by peer review) is the author/funder. All rights reserved. No reuse allowed without permission.

69. De León, P.; Marco, S.; Isiegas, C.; Marina, A.; Carrascosa, J. L.; Mellado, R. P., Streptomyces lividans groES, groEL1 and groEL2 genes. Microbiology 1997, 143 (11), 3563-3571.

70. Wuebbens, M. M.; Rajagopalan, K., Structural Characterization of a Molybdopterin Precursor. J Biol Chem 1993, 268 (18), 13493-13498. 